\begin{tabular}{|c|c|c|}
\hline $\begin{array}{l}\text { I. Rapope No. } \\
\text { FHWA-TS-88-021 }\end{array}$ & 2. Governmen Aeceasion No. & 3. Reripiont' Centelog No. \\
\hline \multirow{2}{*}{\multicolumn{2}{|c|}{$\begin{array}{l}\text { 4. Tirle and Subrifle } \\
\text { Long-Term Evaluation of the Acoustic Emission Weld } \\
\text { Monitor }\end{array}$}} & \multirow{2}{*}{$\begin{array}{l}\text { 5. Repen Det } \\
\text { February } 1988 \\
\text { 6. Pupforming Orgenisarion Cod }\end{array}$} \\
\hline & & \\
\hline $\begin{array}{l}\text { 7. Author! B) } \\
\text { Theodore Hopwood II }\end{array}$ & & $\begin{array}{l}\text { 8. Parferming Orgenization Report No. } \\
\text { UKTRP-88-6 }\end{array}$ \\
\hline \multirow{3}{*}{\multicolumn{2}{|c|}{$\begin{array}{l}\text { 9. Pafoming Orgenisefion Nome And Adress } \\
\text { Kentucky Transportation Research Program } \\
\text { College of Engineering } \\
\text { University of Kentucky } \\
\text { Lexington, KY } 40506-0043\end{array}$}} & 10. Werk Unit No. (TRAIS) \\
\hline & & $\begin{array}{l}\text { 11. Contrees or Grent No. } \\
\text { DTFH61-86-C-00118 }\end{array}$ \\
\hline & & \multirow{2}{*}{$\begin{array}{l}\text { 13. Type of Repopf and Pariod Covered } \\
\text { Fina1 } \\
\text { September 1986-February } 1988\end{array}$} \\
\hline \multirow{2}{*}{\multicolumn{2}{|c|}{$\begin{array}{l}\text { 12. Spenswing Agency Neme and Address } \\
\text { Federal Highway Administration } \\
\text { office of Implementation } \\
\text { Engineering and Highway Operations } \\
\text { McLean, Virginia 22101 }\end{array}$}} & \\
\hline & & 14. Sponsering Ageney Codo \\
\hline
\end{tabular}

15. Supplomensary Notes

FHWA Contract Manager: Terry D. Halkyard (HRT-10)

16. Abspeger

The Kentucky Transportation Research Program conducted an extended $10-$ month evaluation of the Acoustic Emission Weld Monitor (AEWM) in a bridge fabrication shop. That device was used to detect welding flaws during typical production of butt-welds on flanges and webs used in steel bridges. A total of 153 welds were monitored.

AEWM test results were compared with visual inspection and double-blind results of conventional nondestructive testing routinely conducted on the welds. The AEWM did not miss any flaws detected visually or by nondestructive testing. Three AEWM flaw indications were confirmed by conventional nondestructive testing (radiography).

A large number of AEWM indications were not related to any detected flaws (228 of 263 indications). Those were attributed to AE noise that occurs away from the weld and small flaws that were either missed or overlooked by visual and nondestructive inspection or were removed prior to inspection by normal fabrication procedures.

The AEWM has shown the sensitivity to detect AWS code-rejectable defects. In part, the high number of overcalls was caused by use of excessive system sensitivity. Due to the success of the unit in detecting flaws, further development is warranted. Specific recomendations for further research are provided.

17. Hoy Ward:

acoustic emission

bridges

fabrication

nondestructive testing

steel welding

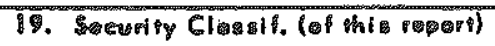

Unclassified
16. Dispribution Sigtement

This document is available to the public through the National Technical Information Service, Springfield, Virginia 22161

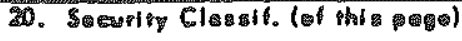

Unclassified
21. No. P P

68
22. Priee 



\section{Long-Term Evaluation of the Acoustic Emission Weld Monitor}

Repor No. FHWA-TS-88-021

Prepared by

Kentucky Transportation Research Program

University of Kentucky

533 South Limestone Street

Lexington, Kentucky 40506

Prepared for

Federal Highway Administration

U.S. Department of Transportation

Washington, D.C. 20590

February 1988 
PREFACE

This study is an investigation of the long-term fabrication shop performance of the Acoustic Emission Weld Monitor (AEWM) covering field testing conducted between January and october 1988. The work was performed in a welding shop that routinely fabricates welded steel bridges for a number of states.

The study is a continuing research effort that initiated with the development and laboratory testing of the AEWM by the GARD Division of Chamberlain Manufacturing Corporation of Niles, Mllinois. That work, sponsored under Federal Highway Administration (FHWA) Contract DTFH61-80-C0083, was completed in 1984.

As a follow up to that effort, the Kentucky Transportation Research Program (KTRP) conducted a series of demonstrations and a preliminary evaluation of the unit for the FHWA in 1985. The AEWM was demonstrated to personnel from 20 state highway agencies representing FHWA Regions 1, 3, 4 and 5. The demonstrations were conducted at three different fabrication shops in Pennsylvania, Georgia, and Wisconsin.

The AEWM also was used by KTRP to monitor large weldments fabricated for the Wisconsin Department of Transportation in September 1986. Additionally, the AEWM has been successfully used to detect fatigue cracks on in-service steel bridges. An Acoustic Emission Bridge Monitor (AEBM) is presently being developed by GARD under FHWA Contract DTFH61-86-R-00072 and is to be completed in October 1988.

This study is sponsored by the Federal Highway Administration, Office of Implementation. High Steel Structures Incorporated of Lancaster, Pennsylvania was the host fabrication shop for the AEWM testing. Four state highway agencies cooperated in this study by allowing welding operations on their bridge members to be monitored. Those agencies included: New York State Department of Transportation, Maryland Department of Transportation, Vermont Agency of Transportation, and New Jersey Department of Transportation. GARD, a subcontractor to KTRP, provided technical assistance for the AEWM. 


\section{METRIC (SI*) CONVERSION FACTORS}

APPROXIMATE CONVERSIONS TO SI UNITS

Symbot You Know Muitlply $3 y$ To find

\begin{tabular}{lll} 
& \multicolumn{2}{c}{ LENGTH } \\
\cline { 2 - 3 } inches & 254 & millimetres \\
feet & 0.3048 & metres \\
yards & 0.914 & metres \\
milles & 1.61 & kilometres
\end{tabular}

$$
\text { AREA }
$$

square inches 645.2 millmetres squared $\mathrm{mm}^{2}$ square foet

square yards

0.0929

metres squared

0.092

metres square

acres

0.395

hectares

\section{MASS (weight)}

APPROXIMATE CONVERSIONS TO SI UNITS

Symbol Whon You know sustiply By To Find Symbol

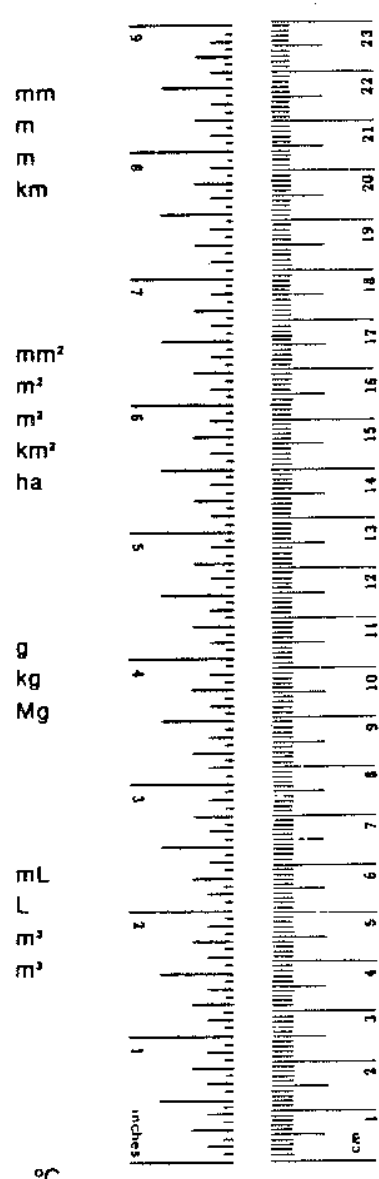

$\begin{array}{cllll}\mathrm{mm} & \text { millimetres } & 0.039 & \text { inches } & \text { in } \\ \mathrm{nm} & \text { metres } & 3.28 & \text { feet } & \mathrm{ft} \\ \mathrm{m} & \text { metres } & 1.09 & \text { yards } & \text { yd }\end{array}$

\begin{tabular}{cllll} 
& \multicolumn{3}{c}{ AREA } & \\
\cline { 2 - 5 } $\mathrm{mm}^{2}$ & millimetres squared & 0.0016 & square inches & $\mathrm{in}^{2}$ \\
$\mathrm{~m}^{2}$ & metres squared & 10.784 & square feet & $\mathrm{ft}^{2}$ \\
$\mathrm{~km}^{2}$ & kilometres squared & 0.39 & square mlles & $\mathrm{mi}^{2}$ \\
$\mathrm{ha}$ & hectores $\left(10000 \mathrm{~m}^{2}\right)$ & 2.53 & acres & $\mathrm{ac}$
\end{tabular}

\begin{tabular}{cllll} 
& \multicolumn{4}{c}{ MASS (weight) } \\
\cline { 3 - 4 } $\mathrm{g}$ & grams & 0.0353 & ounces & \\
$\mathrm{kg}$ & kllograms & 2.205 & pounds & or \\
$\mathrm{Mg}$ & megagrams (1 $000 \mathrm{~kg})$ & 1.103 & short tons & $\mathrm{T}$
\end{tabular}

short tons $1000 \mathrm{~kg}) 1.103$ it

\begin{tabular}{|c|c|c|c|c|}
\hline \multirow[b]{2}{*}{$\mathrm{mL}$} & \multirow[b]{2}{*}{$\begin{array}{l}\text { millilitres } \\
\text { litres }\end{array}$} & \multicolumn{2}{|c|}{ VOLUME } & \\
\hline & & 0.034 & fluid ounces & fl oz \\
\hline $\mathrm{m}^{\prime}$ & $\begin{array}{l}\text { IItres } \\
\text { metres cubed }\end{array}$ & 35.315 & cubic feet & $\mathrm{ft}^{3}$ \\
\hline $\mathrm{m}^{3}$ & metres cubed & 1.308 & cubic yards & $\mathrm{yd}^{3}$ \\
\hline
\end{tabular}

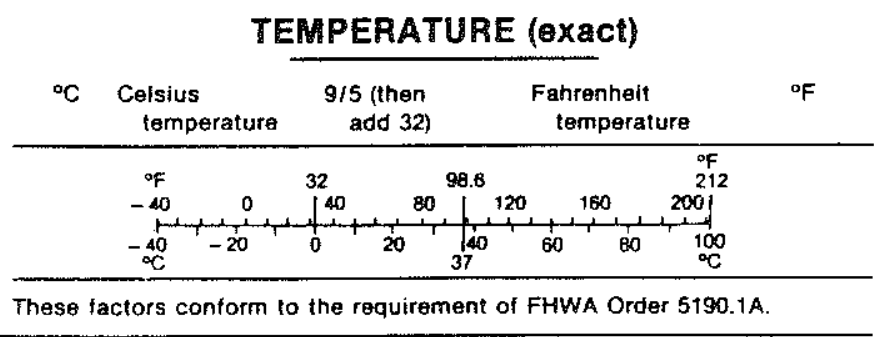

These factors conform to the requirement of FHWA Order $5190.1 \mathrm{~A}$.

temperature subtracting 32) temperature 
I. Introduction . . . . . . . . . . . . . . . . . . . 1

II. Operation of the AEMM. . . . . . . . . . . . . . . . . 3

III. Preliminary Study Efforts. . . . . . . . . . . . . . 7

Test Objectives . . . . . . . . . . . . . . 7

Fabrication Shop Selection. . . . . . . . . . . . . 7

AEWM Weld Testing Procedure . . . . . . . . . 8

Project Staffing. . . . . . . . . ........ . 9

Test Equipment.................... 10

IV. Fabrication Shop Monitoring. . . . . . . . . . . . . 13

Test Routine........................ 13

Progress of AEWM Testing. . . . . . . . . . . . . . 19

Weld Procedure Prequalification . . . . . . . . . . 20

Test Problems . . . . . . . . . . . . . . . . 21

Submerged-Arc Welding and Flaws . . . . . . . . . . . 24

Role of the Welder in Quality Control . . . . . . . . . . 24

F1aws Encountered During Testing. . . . . . . . . 27

V. Data Analyses and Discussion ................. 33

AEWM Test Results . . . . . . . . . . . . . 33

AEWM Flaw Detection Performance . . . . . . . . . . 33

AEWM Performance During Shop Testing. . . . . . . . . . 46

VI. Conclusions. . . . . . . . . . . . . . . 47

VII. Recommendations. . . . . . . . . . . . . . . . 49

Elimination of AEWM False Indications . . . . . . . . . 49

AEWM Reconfiguration. . . . . . . . . . . . . . . 49

Future AEWM Testing .................... 53

Future Application of the AEWM. . . . . . . . . . 55

VIII. Appendix - AEWM Report Form . . . . . . . . . . . . 57

IX. References ...................... 59 


\section{LIST OF FIGURES}

Figure

Page

1. Ultrasonic Inspection of Flange Weld. . . . . . . . . . . 2

2. Use of the AEWM to Inspect Large Weldment . . . . . . . . . 2

3. AEWM Processing Flow Chart for Flaw Detection ......... 5

4. Schematic of Typical Butt-Weld Showing Normal Transducer

Placement . . . . . . . . . . . . . . . 5

5. Magnetic Hold-Down Assemblies Housing the Preamplifiers and

Transducers . . . . . . . . . . . . . . . 14

6. Attaching Transducer to Flange Weld . . . . . . . . . . 14

7. Calibrating the AEWM Prior to Monitoring Weld . . . . . . 15

8. Welder Performing Semi-Automatic Submerged-Arc Weld on Web. . . . 17

9. Semi-Automatic Submerged-Arc Welding Gun Depositing "A" Face

Weld on Beveled Side of Flange. . . . . . . . . . . 17

10. Carbon-Air Arc Backgouging on Back Side of a Flange Weld. . . . 18

11. Depositing Weld on Flange .................. 23

12. Welder Chipping Flux during Welding Operation . . . . . . . 23

13. Grinding a Surface Blemish Prior to Depositing a Succeeding

Weld Pass ................... 26

14. Manual Submerged-Arc Weld Repair of Large Weldment. . . . . . . 26

15. AEWM Flaw Indication from Web Welding Operation . . . . . . . 28

16. Slag Stringer (Figure 15) Revealed after Backgouging. . . . . 28

17. Weld "Roll" in Flange Weld. . . . . . . . . . . . 29

18. Slag Inclusion in Weld (Figure 17) Revealed by Backgouging. . . . 29

19. Weld Irregularity Caused by Temporary Loss of Flux. . . . . . 30

20. Flaw at Weld Termination (Slag and Porosity) Detected by AEWM . . 30

21. Trapped Surface Weld Slag Detected by AEWM during Root Pass

Weld and Subsequently Repaired by Grinding. . . . . . . . . 31

22. Transducer Assembly Coupled to Weldment . . . . . . . . . 52 


\section{LIST OF TABLES}

Table

Page

1. AEWM Fabrication Shop Test Data . . . . . . . . . 34

2. Summary of AEWM Testing (Web Welds) . . . . . . . . . 41

3. Summary of AEWM Testing (Flange Welds). . . . . . . . . 41

4. AEWM Indication Summary (Web Welds) . . . . . . . . . 43

5. AEWM Indication Summary (Flange Welds). . . . . . . . . 44 



\section{INTRODUCTION}

Most American bridges constructed with spans exceeding 150 feet incorporate welded steel fabrication. The Federal Highway Administration (FHWA) has sought to improve nondestructive testing technology applied to inspection of fabrication shop welds. Currently used methods (including ultrasonic testing, radiography, dye-penetrant testing, and magnetic-particle testing) are all over 40 years old. Those methods are expensive to apply and require a great deal of operator interpretation for flaw evaluation (Figure 1). The main drawback in applying those methods in fabrication shops is that they are quality-assurance ( $Q A)$ oriented. They are usually limited to tests on completed welds wherein any evaluations of defect-level flaws result in repairs. The repair process is expensive, tedious, and sometimes may result in the introduction of additional defects.

Improved nondestructive testing (NDT) technology is needed that allows weld evaluation to be conducted at a lower level of fabrication prior to weld completion. To achieve that goal, the FHWA sponsored research for development and testing of the Acoustic Emission Weld Monitor (AEWM) (Figure 2). The AEWM "listens" to welds as they are being deposited and automatically detects and locates any weld-related flaw activity. That capability could provide inexpensive cost quality-control (QC) inspection that, in turn, would allow fabricators to lower welding costs and provide better quality welds to highway agencies. 


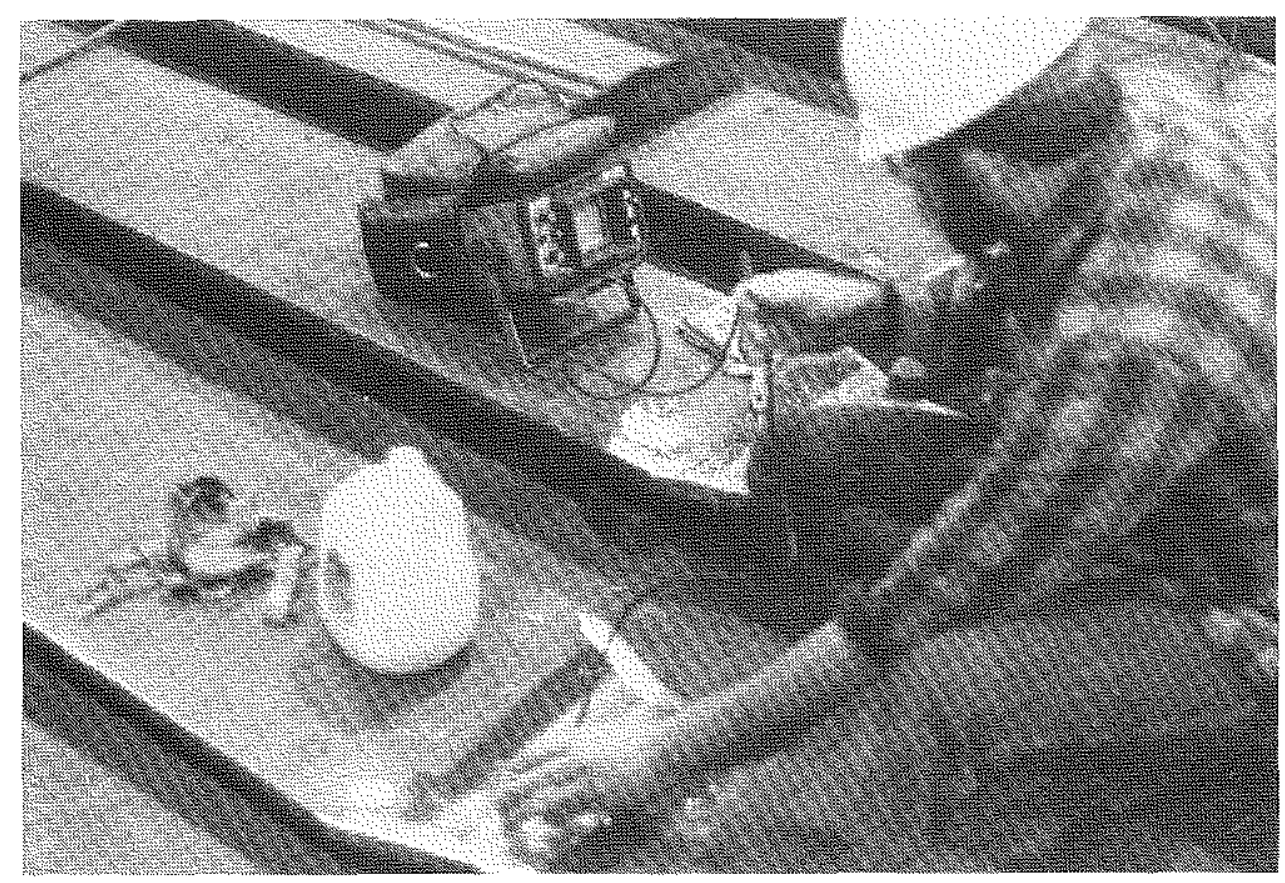

Figure 1. Ultrasonic Inspection of Flange Weld.

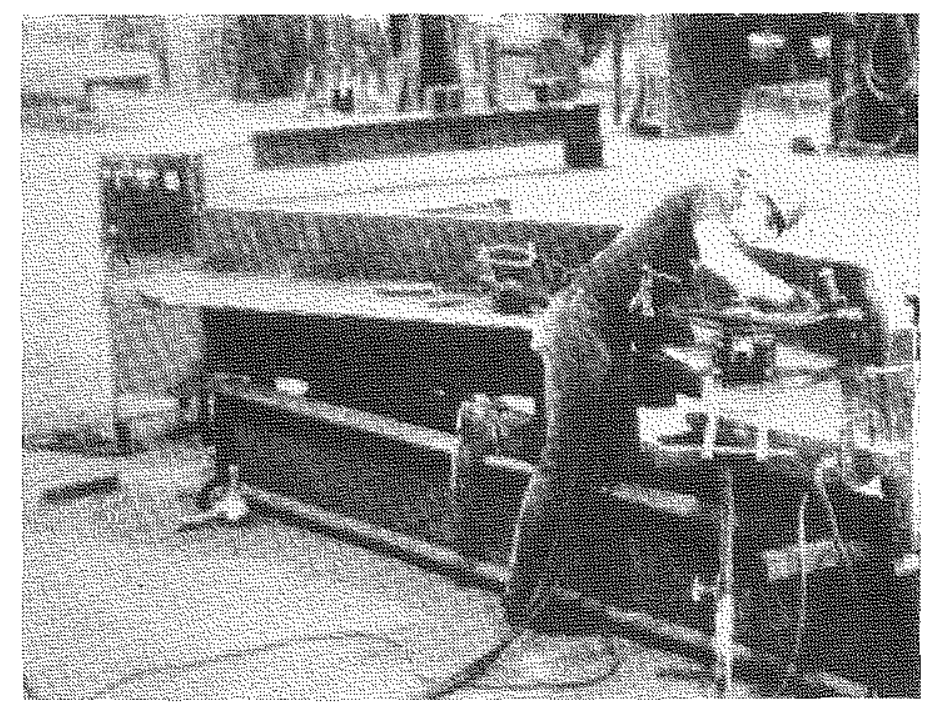

Figure 2. Use of the AEWM to Inspect Large Weldment (at Phoenix Steel Inc., Eau Claire, Wisconsin, Septenber 1986). 


\section{OPERATION OF THE AEWM}

The functional operation of the AEWM has been discussed in other reports and will be explained only briefly herein $(1,2)$. The AEWM performs weld flaw detection in real time. It employs pattern recognition to discriminate between normal background $\mathrm{AE}$ noises created by welding processes and $\mathrm{AE}$ events due to the formation of flaws such as slag inclusions or cracks. The AEWM pattern-recognition process subjects each $\mathrm{AE}$ event to a series of sequential tests. The flaw detection model requires a three-step testing process as shown on the flow chart in Figure 3. After computing an $\mathrm{AE}$ ringdown count (RDC) for each separate $\mathrm{AE}$ event, the first test is applied. If the ringdown count lies within preset limits (usually 100 to 1,000 counts), an event is passed to the second test for $\mathrm{AE}$ event rate. This test requires that some number of $\mathrm{AE}$ events, which have passed the RDC test, occur within a preset time interval (usually 1 to 2 seconds). The final test determines whether all the events that have passed the previous two tests originated from the same location or at least within a predetermined location tolerance (usually \pm 1 inch). The AEWM also subjects the $\mathrm{AE}$ events to frequency spectra analyses for flaw characterization. Indications with high-frequency components are categorized as crack-related. Others with lower-frequency components are categorized as unclassified flaws.

The combination of rate and location tests provides very high discrimination against interfering background weld noise. The assumptions employed in the pattern-recognition process are 1) a growing flaw will produce higher rates of $A E$ activity than noise sources and 2) a flaw, being a localized phenomenon, will produce a higher rate of AE activity from a specific location than noise. This form of AE monitoring differs from conventional $\mathrm{AE}$ methods in that it is event-rate based and employs a multiparametric filtering process to discriminate between noise sources and weld flaws in real time.

AEWM testing uses linear flaw location. Two AE sensors (transducers) are normally required to perform those tests. In this research, standard piezoelectric transducers were employed having peak resonant frequencies in the range between 150 to $200 \mathrm{kHz}$. The transducers were wired to GARD $0 \mathrm{~dB}$ gain preamplifiers, which were connected by coaxial cables to analog modules mounted in the AEWM. 
The transducers are attached to a weldment 6 inches offset from a weld line and 2 inches from the plate edges (Figure 4). As the welding operation progresses, the two transducers monitor acoustic emissions sending electrical signals to the AEWM for processing. Once the AEWM determines that a weld flaw has been created, a flaw indicating lamp on the face of the instrument panel of the AEWM will extinguish, thereby alerting the AEWM operator that a flaw has occurred at a point along the weld line.

The AEWM is capable of "stand-alone" operation. In that mode, the unit is calibrated and operated entirely in a self-contained manner. The AEWM flaw indicating lamp informs the operator that a defect has occurred. Then, the operator can approximately locate the flaw in a position between the two transducers to within $1 / 16$ of the transducer spacing from location indications provided by a 16-bit light-emitting diode (LED) pane1. Also, the flaw category determined by the AEWM frequency spectra analyses will be displayed on the LED panel. In the present AEWM, the test data are retained for up to 256 weld tests (as long as the AEWM is powered). That data can be recalled and displayed on the LED pane1. Otherwise, it must be output to a printer or a disk recorder. A video terminal may be used to support the "stand-alone" operation to provide better location of any defects occurring between the transducers (down to a 1 -inch resolution).

The system also may be operated in a "data-recording" mode, which allows the $A E$ parameters to be stored on a floppy disk and later retrieved or reprocessed for hardcopy backup or for post-test analysis of $\mathrm{AE}$ data using various flaw models. It is time consuming to calibrate the AEWM in that mode of operation, and difficult to maintain the disk drive in long-term fabrication-shop use. 


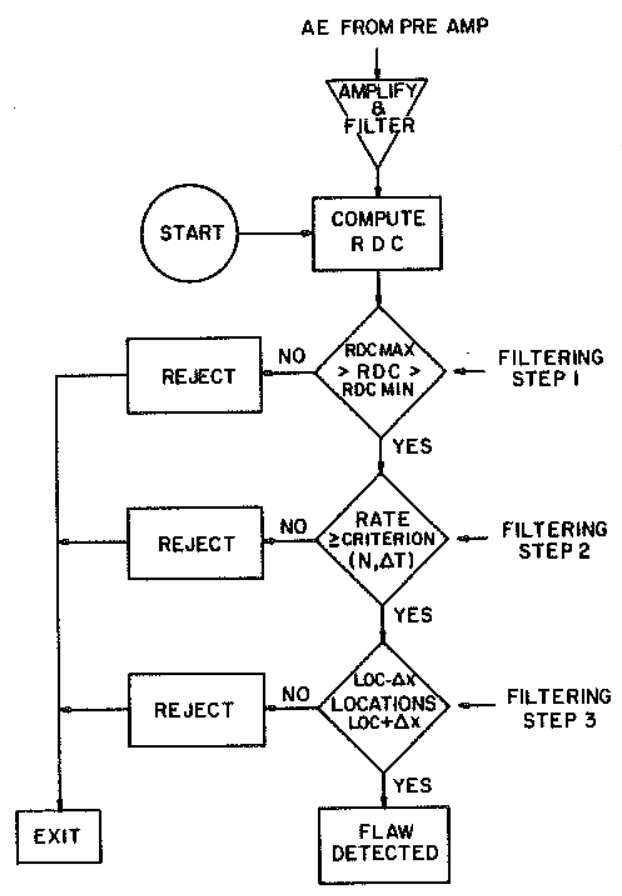

Figure 3. AEWM Processing Flow Chart for Flaw Detection.

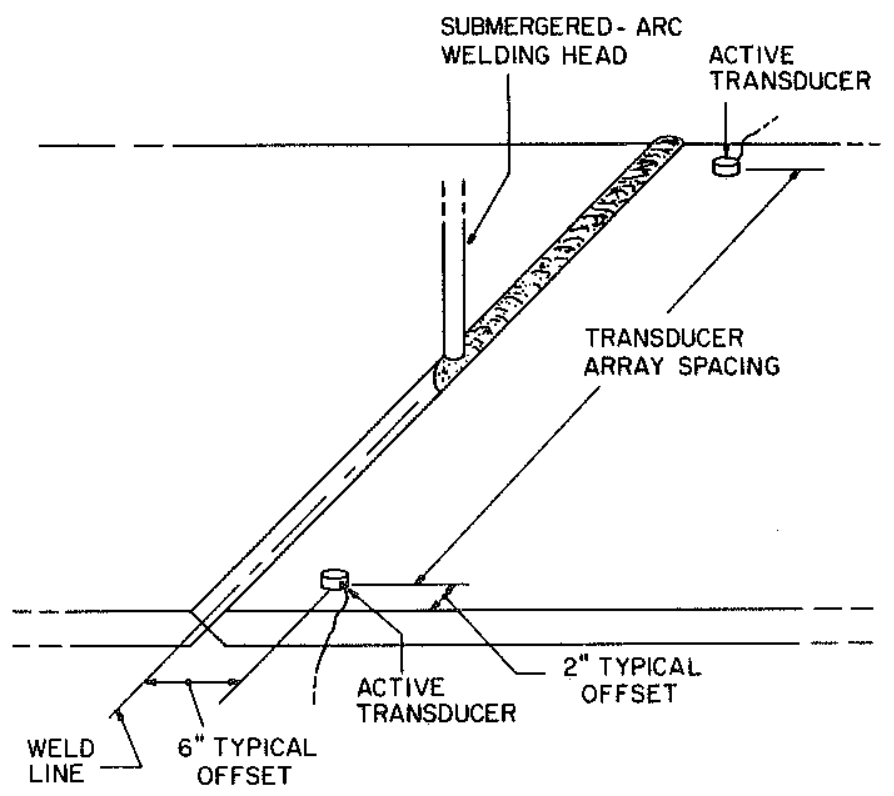

Figure 4. Schematic of Typical Butt-Weld Showing Normal Transducer Placement. 



\section{PRELIMINARY STUDY EFPORTS}

\section{TEST OBJECTIVES}

In September 1986, KTRP received FHWA Contract DTFH61-86-R-00118 to perform a long-term shop evaluation of the AEWM. The stated objectives of the program were 1) to perform monitoring operations of fabrication-shop welds (establish a test data base), 2) to correlate AEWM test results with those obtained using conventional code-based NDT methods, 3) to evaluate the performance of AEWM and recommend any follow-up actions or reconfigurations of the unit, and 4) to prepare recommendations for code modifications to support the deployment of the AEWM in fabrication shops to inspect steel weldments for highway bridges.

Those formal objectives were necessary to establish the performance characteristics of the unit and to determine whether further action was warranted. Additionally, KTRP had several informal objectives necessary to extend the utility of the unit for use by fabrication-shop personnel: 1) to determine whether the AEWM could be used by unskilled operators; 2) to determine whether the AEWM would significantly affect the rate of shop welding; 3) to determine if any additional benefits such as cost savings, improved welding operators, better end-products, easing of welding specifications, or weld-qualification testing were possible; and 4) to obtain a sufficiently large test record to persuade states and code committees that the system might warrant consideration for adoption in various welding codes, regulations, and specifications.

\section{FABRICATION SHOP SELECTION}

The first task of this study was to locate a fabrication shop that would allow the use of the AEWM to inspect welding operations. The plant selected was High Steel Structures Inc. of Lancaster, Pennsylvania. There were several reasons for that choice. The shop was located within a reasonable distance of both the KTRP laboratory and the FHWA offices in the Washington, D.C. area. High Steel was very actlve in welded steel-bridge fabrication for a large number of states, providing high visibility of the AEWM to state personnel at the plant. Also, it offered the opportunity to inspect a large number of welds. High Steel had been host for a previous AEWM demonstration, and the shop personnel were familiar with the unit and its interaction with their operations. 
In November 1986, FHWA, High Steel, and KTRP personnel met to establish guidelines for employing the AEWM at the High steel fabrication shop. At that time, it was determined test results should be maintained separate from conventional NDT information normally furnished to states. This was due to the experimental nature of the $A E W M$ and the need to prevent any hardship for High Steel should questions arise about AEWM test results. The decision was made to acquire conventional NDT results separately from those of the AEWM (in a double-blind manner) and compare them using an independent third party, the High Steel QC personnel.

AEWM test results had to be correlated with each weld member and transmitted independently in an identifiable form to the shop QC personnel for test comparisons. Also, it was determined that only web and flange butt welds would be monitored since no significant background laboratory or controlled experiments had been performed using the AEWM to monitor flange-to-web connections (with the exception of the large full-penetration weldments previously monitored by KTRP investigators for the Wisconsin Department of Transportation). The test duration was set at 6 months. During that time, KTRP personnel anticipated they would be able to monitor 100 to 125 welds.

\section{AEWM WELD TESTING PROCEDURE}

After the meeting with FHWA and High Steel personnel, the decision was made to emphasize the testing of web butt welds. Web monitoring would produce more weld length inspected per test than flange monitoring. Therefore, monitoring of flange butt welds was considered of secondary importance. Also, it was determined that 100 percent AEWM monitoring of each weld would be desirable since conventional NDT results would be based on an entire weld and It would be difficult to correlate test results if only a portion of a weld was monitored. Transmission of data from KTRP personnel to shop QC personnel and then to the KTRP principal investigator required preparation of an AEWM report form (Appendix). The form contained an individual number for each AEWM test and a space for each shop weld-identification number allowing High Steel QC personnel to correlate the AEWM tests with conventional NDT results. Also, the test date and shift number during which the monitoring was performed was to be noted. The form contained spaces for summary information on the amount of material tested and also on whether a defect was encountered by either the AEWM and/or conventional nondestructive testing. A small diagram was included 
to note the welding direction on each side of the weldment.

A procedure was formulated whereby the Number 1 transducer of the array was always placed at the starting point of the welding operation. However, it was necessary to determine where the weld was started in relation to the initial weld side (or "A face") of the plate. In some cases, it was possible for the welder to begin welding on the backside (or "B face") from either end of the weld in relation to the starting point of the pass on the "A face" of the plate. This was noted by circling the arrow shown on the schematic and indicating it was the welding direction for the "A face" and then noting the starting point of the back side ("B face") weld in relation to the "A face" weld. This allowed determination of defect location if one was encountered on either side of the plate in relation to the transducer placement.

The FHWA required additional information, including type of steel welded, plate thickness, weld preparation, plate width, wire type, flux, welding amperage, voltage, and speed, and preheat. The important AEWM test variables included the system gain for each channel and the sensor spacing, which was usually 4 inches less than the total plate width. Spaces were provided on the form to record that information as well as $\mathrm{AE}$ test results for seven passes on each side of a weld. Also, spaces were included for any comments by the KTRP technician and for comments by shop QC personnel.

\section{PRONRCT STAFFING}

The principal investigator prepared the test program. Also, he visited the fabrication shop at three-week intervals to inspect monitoring operations and review test results. This allowed close control of shop monitoring and provided him an opportunity to experiment with various test methods.

The KTRP technician who performed the shop tests had no previous experience with nondestructive testing or acoustic emission. Due to the relative ease of operating the $A E W M$ and the noninvolvement of the operator in defect detection and interpretation, his inexperience was not considered a detriment. Prior to the shop tests, he received two weeks of training on the unit. The training consisted of "hands-on" experience with the AEWM and instruction on the AEWM operational manual. The technician did not have experience with the use of the AEWM on welding operations until the shop testing commenced. 
The KTRP technician was assigned to conduct routine testing of the shop welds using AEWM. His daily duties were 1) to contact the shop foreman and locate a site of ongoing butt-welding operations, 2) to set up the AEWM and monitor welding activity at that location, 3) to record test results on AEWM report forms, 4) to pass those forms to shop QC personnel for correlation with conventional NDT results, 5) to $\log$ all test work on a weekly basis, and 6) to keep back-up copies of the report forms. Additiona11y, the technician was to forward the completed (correlated) report forms to the KTRP principal investigator and contact him should any problems arise with the test program or equipment.

\section{TEST EQUTPMENT}

The shop tests were performed using the AEWM in the "stand-alone" mode. This was prompted by several facts. The technician did not have sufficient initial experience or training to operate the equipment in the "datarecording" mode. Also, it required considerable time to calibrate the unit in that mode of operation. Additiona11y, the "data-recording" mode required the use of a Pertec floppy disk recorder, which was the sole data-recording method supported by the AEWM. Unfortunately, the recorder company no longer existed. So, it was unwise to operate the disk drive for long periods in a fabrication shop and risk getting it damaged. The test results had to be transferred to the shop QC personnel in hardcopy form. It was more efficient for the technician to immediately record results of each weld pass monitored onto the AEWM report form than to retrieve them from floppy-disc records.

The AEWM was operated at an intermediate gain level (sensitivity) between 50 to 70 decibels in an attempt to minimize "overcalls" (flaw activity that was not confirmed by visual inspection or other nondestructive testing). Previous experience at the Phoenix Steel fabrication shop in Eau Claire, Wisconsin, prior to this study, indicated this was the best approach to $\mathrm{AE}$ weld monitoring.

The equipment included the Acoustic Emission Technology (AET) 175L transducers, which had been employed in previous research. Several special AET 175 transducers were acquired with an integral lead wire from the transducer consisting of RG 58 coaxial cable 6-feet long. Those units were more damage-resistant than normal AET 175 transducers and, therefore, better sulted for harsh shop use. Temperatures measured on flange welds exceeded 500

${ }^{\circ} \mathrm{F}$ (especially when preheating was used). As the temperature rating for the 
AET 175L transducers was limited to around $300{ }^{\circ} \mathrm{F}$, transducers capable of sustaining higher temperatures were needed to test flange welds. Several Physical Acoustic Corporation (PAC) RH15 high-temperature transducers were acquired that were functional to $600^{\circ} \mathrm{F}$. Those transducers had manufacturerspecified resonant frequencies of about $500 \mathrm{kHz}$.

To avoid problems with signal cables connecting the AEWM to the transducer preamplifiers, cable lengths were limited to 50 feet. This provided several benefits. By keeping the cable length to a minimum, problems with electrical (RF) noise and cable coupling were minimized. Also, short cable runs kept the technician close to the weld allowing him to observe welding operations. A portable cart was used to move the AEWM about the shop and provide close access to the welds. On a few occasions, longer cable runs (100-feet long) were required. Those were made by coupling two 50-foot cables together.

To prevent incorrect addressing of the $\mathrm{AE}$ signals, a color-coding system was employed whereby the cables, preamps, transducers, and analog channels were color-coded to denote the Number 1 channel system (yellow) and the Number 2 channel system (red). Also, the 16-bit LED panel on the face of the AEWM was color-coded yellow on the left side and red on the right side to provide consistent addressing of a potential flaw source in reference to transducer placement. A third analog channel on the AEWM could be used for a "lock-out" to prevent out-of-array $\mathrm{AE}$ noise from entering the linear array. To simplify testing operations, that feature was not used. 



\section{FABRICATION SHOP MONITORING}

\section{TEST ROUTINE}

Monitoring operations at High Steel were initiated on January 6, 1987 . A daily test routine was established whereby the KTRP technician would move the AEWM from its storage location to a test site on the shop floor and prepare to monitor welds. Prior to a welding operation, the technician would inspect the steel plates and record the weldment number printed on one plate. Also, he would check the welding machine to determine its voltage and welding-wire feed-rate settings.

Transducer placement and AEWM calibration required about 5 to 10 minutes. This did not substantially interfere with welding operations. The transducers were mounted in hold-down assemblies that also incorporated preamplifiers (Figure 5). Since those assemblies were housed in a single pre-connected unit, they could be quickly attached to the weldment saving much time compared to handling separate components. The technician applied a silicone couplant on the wear faces of the two transducers and then attached them on one side of the weldment adjacent to the weld line (Figure 6). After the technician had determined the plate width and established the transducer spacing, he calibrated the AEWM and prepared for monitoring (Figure 7).

Transducer calibration and coupling was simply verified by using a screwdriver to tap the steel plate adjacent to the transducer. The technician viewed the three $\mathrm{AE}$ activity indicating lights on the face of the AEWM analog modules (channels) as he tapped the steel plate to ascertain that coupling had been achieved. Final gain adjustment was made during the early part of the first (root) weld pass. During that pass, the technician would view the indicating lights as they flickered intermittently due to the AE activity from the welding operation. The preset gain was usually sufficient to properly calibrate the transducers. However, if the indicating Iights on either of the AEWM modules exhibited a low level of $\mathrm{AE}$ activity, the gain was increased. Source-location calibration was not necessary.

When a welding operation commenced, the technician began the monitoring process. During welding, he watched both the welder and the AEWM $f 1$ aw indicating lamp to determine if some event occurred that might produce a flaw indication. 


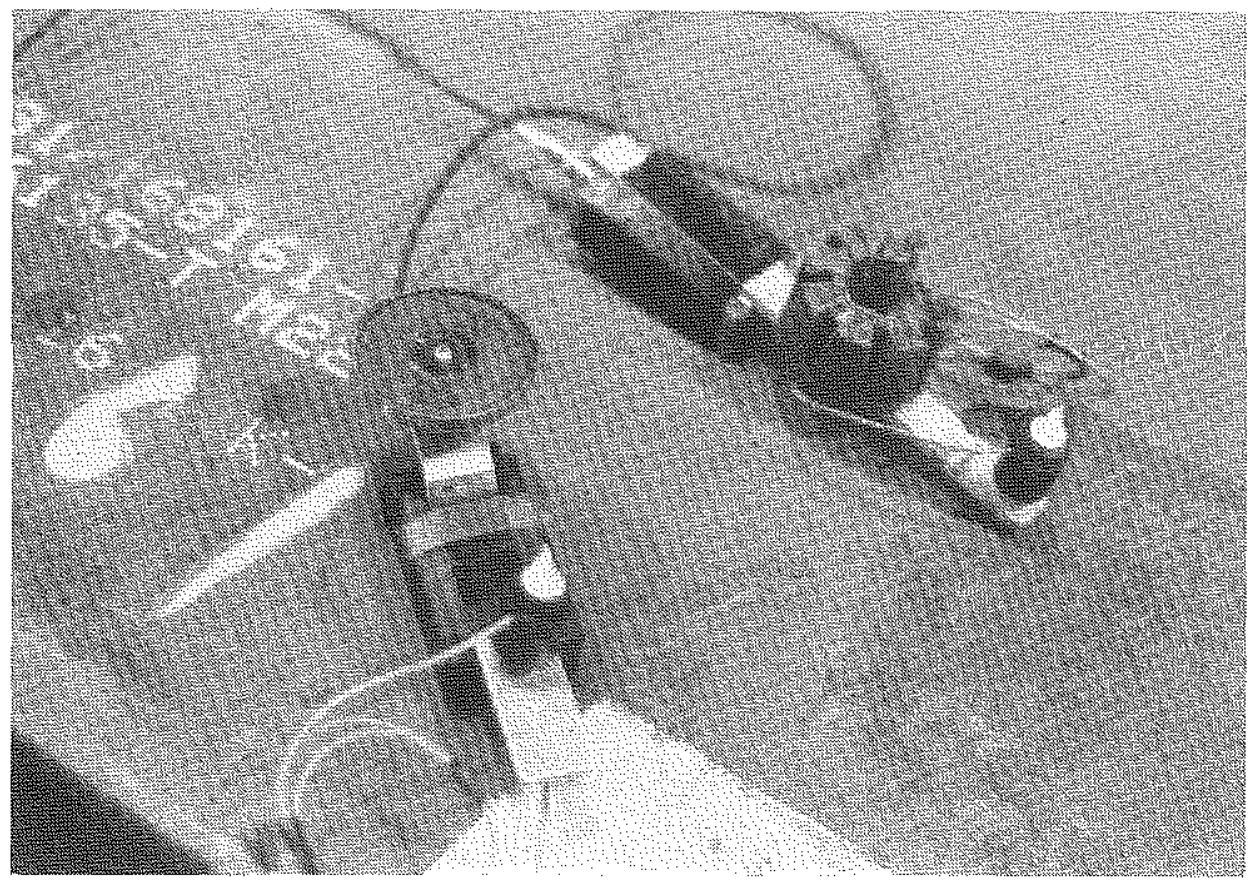

Figure 5. Magnetic Hold-Down Assemblies Housing the Preamplifiers and Transducers (Note the silicone couplant on faces of transducers).

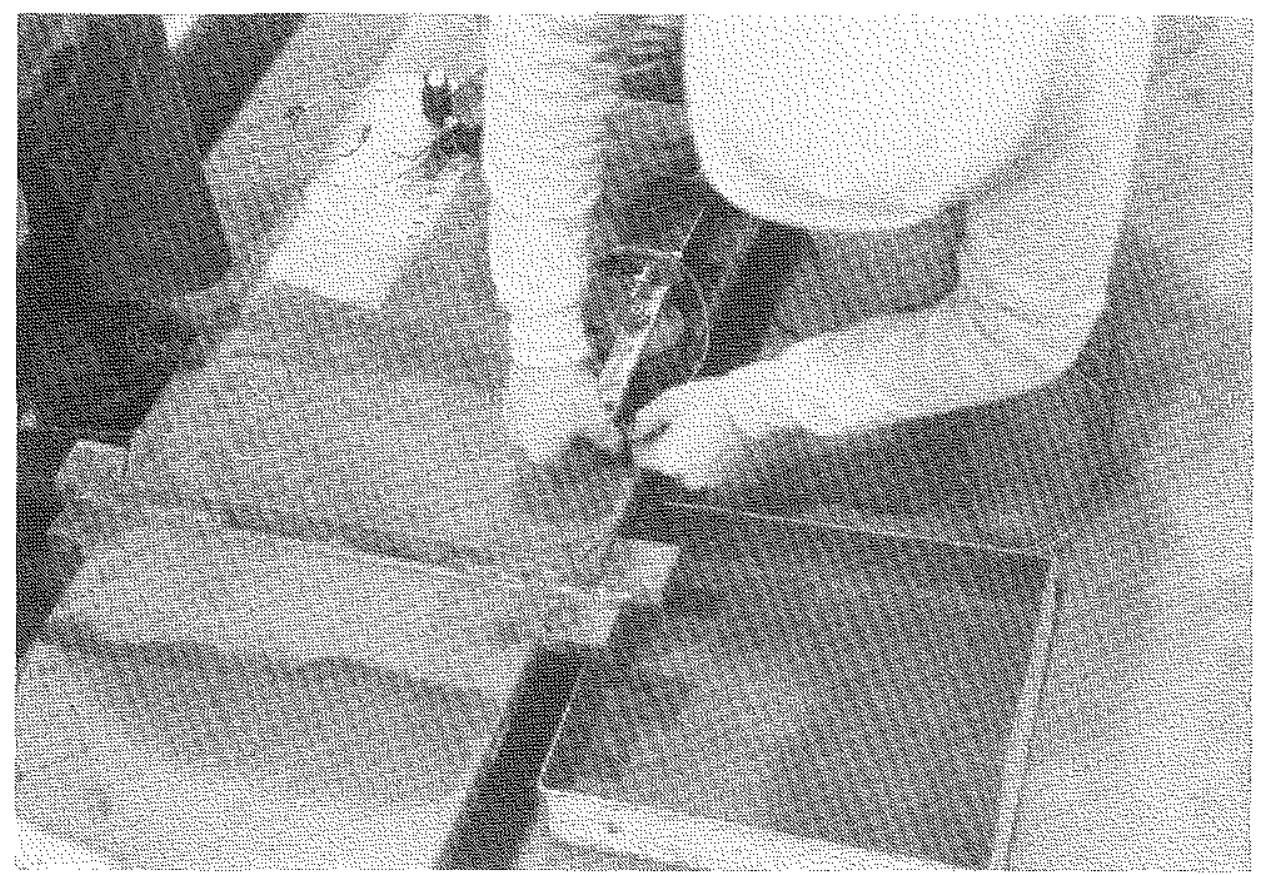

Figure 6. Attaching Transducer to Flange Weld. 


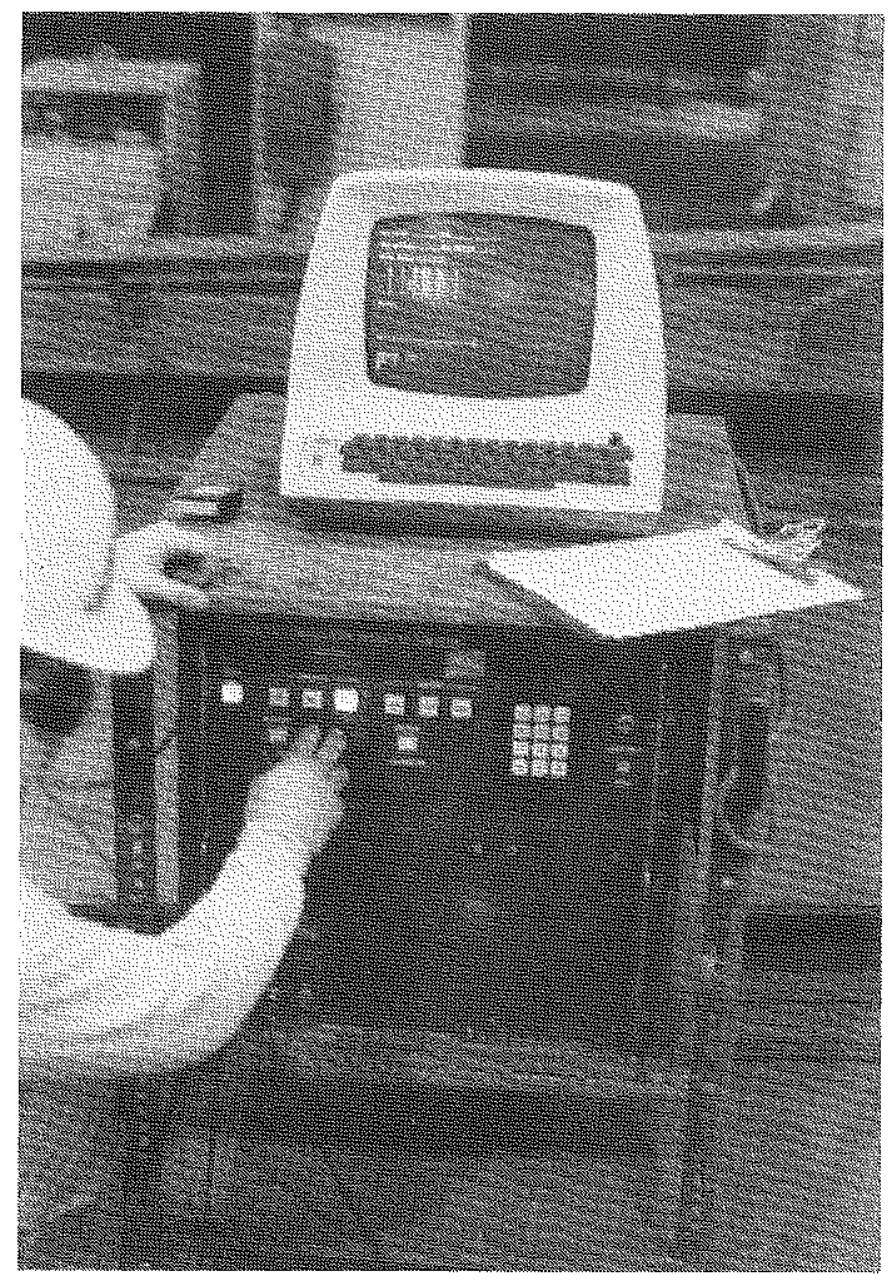

Figure 7. Calibrating the AEWM Prior to Monitoring Weld. 
The AEWM also was connected to a video terminal. Variously, either a Microbee or an ADM 3A terminal was used. The terminal provided a visual readout of the location, classification, and ringdown counts (energy) of any flaw indications after each weld pass was completed.

The fabrication shop employed semiautomatic submerged-arc welding for web and flange butt-welding operations (Figure 8 ). The welding machine was equipped with a hand-held welding gun that contained a rolling wheel to control its travelling speed along a weld (Figure 9). The welding-wire feed rate was automatically controlled by the welding machine. The operator adjusted the vertical offset and lateral position of the welding gun in relation to the weld groove prior to welding. The only manual control required during welding was the lateral positioning of the weld gun as the welder guided it along a weld.

Typically, the shop performed double-bevel groove butt welds. Initially, a single V-groove butt joint was provided between two plates that were fitted and then tack-welded together. The welding operator deposited the root weld pass on the "A face." Typically, two to three passes were required to complete that weld. Prior to turning a weldment, the "A face" weld reinforcement was manually ground flush with the plate. Thereafter, the weldment was turned and the opposite weld face was backgouged to sound metal (Figure 10). Then, a groove was formed on the back side or "B face" with a hand grinder. The welder completed the weld, usually in one or two passes. The weld reinforcement on the back side was subsequently ground flush.

Approximately, 50 percent of all weld metal deposited on webs was removed either by backgouging or grinding.

Normally, flange butt welds required 15-20 passes on the "A face," which contained a plate-thickness transition bevel. Then, the weldment was turned, backgouged, ground, welded, and finish-ground on the back side. In most cases, only one or two passes were required to complete the back-side weld. on a percentage basis, less weld material was removed by backgouging and grinding flange welds than was removed from the web welds.

Conventional NDT operations usually were not performed immediately after weld completion, especially if radiography was used. Radiography required the weldments to be moved to a separate test area at one end of the shop. That was necessary to prevent shop personnel from becoming exposed to radiation. The handling required to move the weldments in and out of the restricted area was an additional cost to the fabricator. In some instances, ultrasonic 


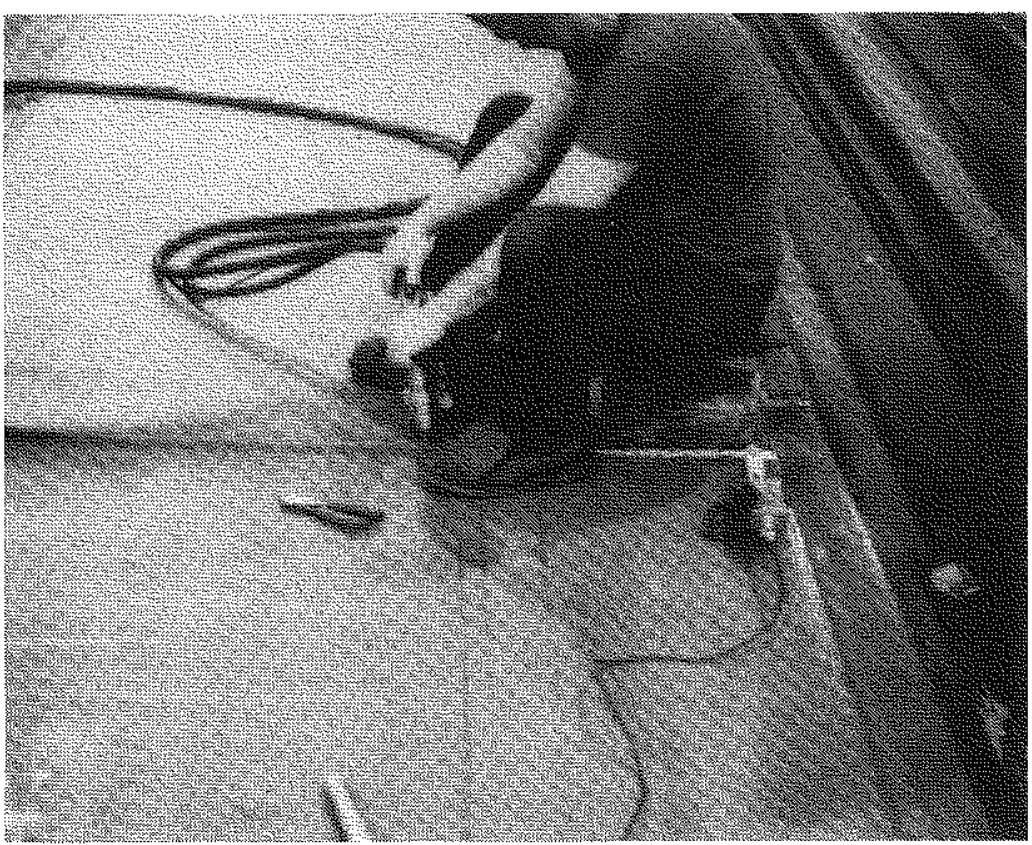

Figure 8. Welder Performing Semi-Automatic Submerged-Arc Weld on Web (Note $A E$ transducers located near edge of plate).

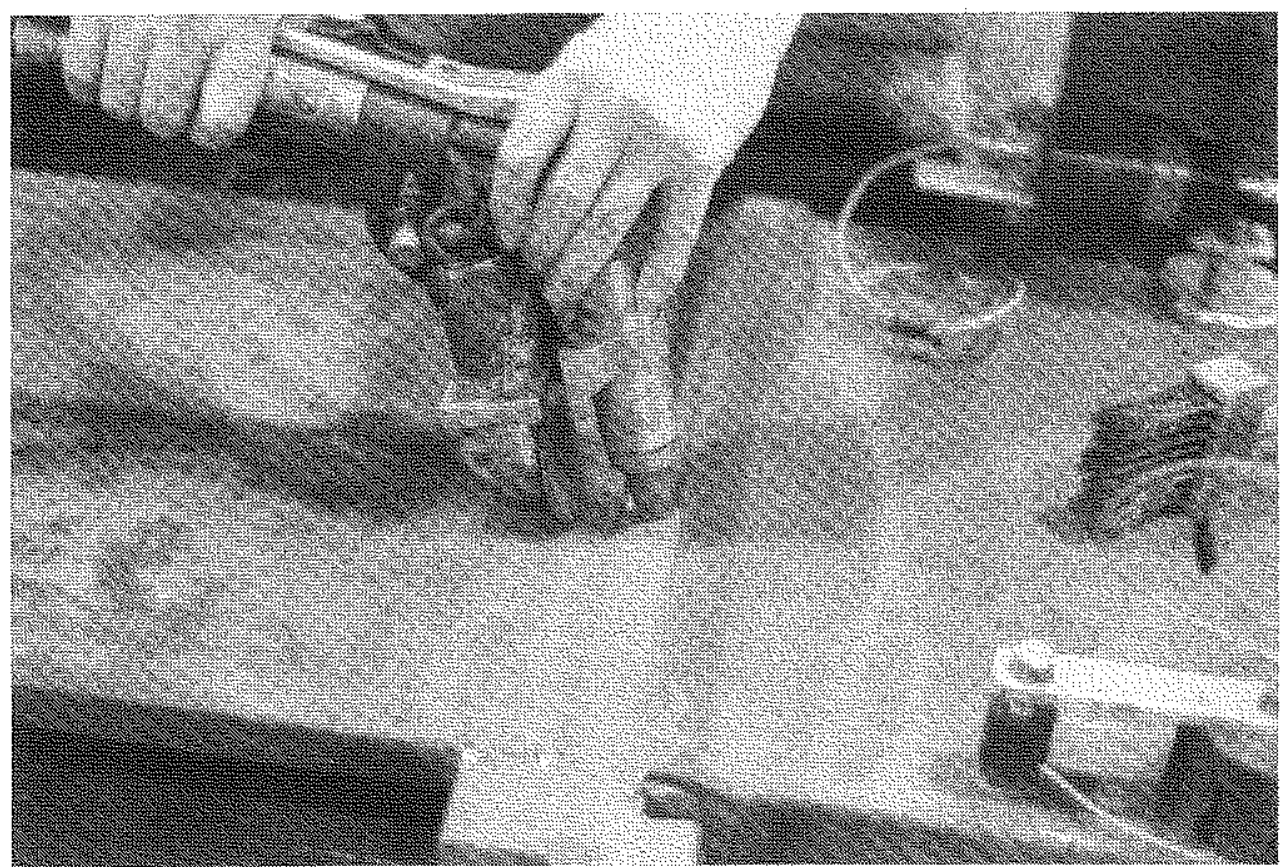
Figure 9. Semi-Automatic Submerged-Arc Welding Gun Depositing "A" Face Weld on Beveled Side of Flange.




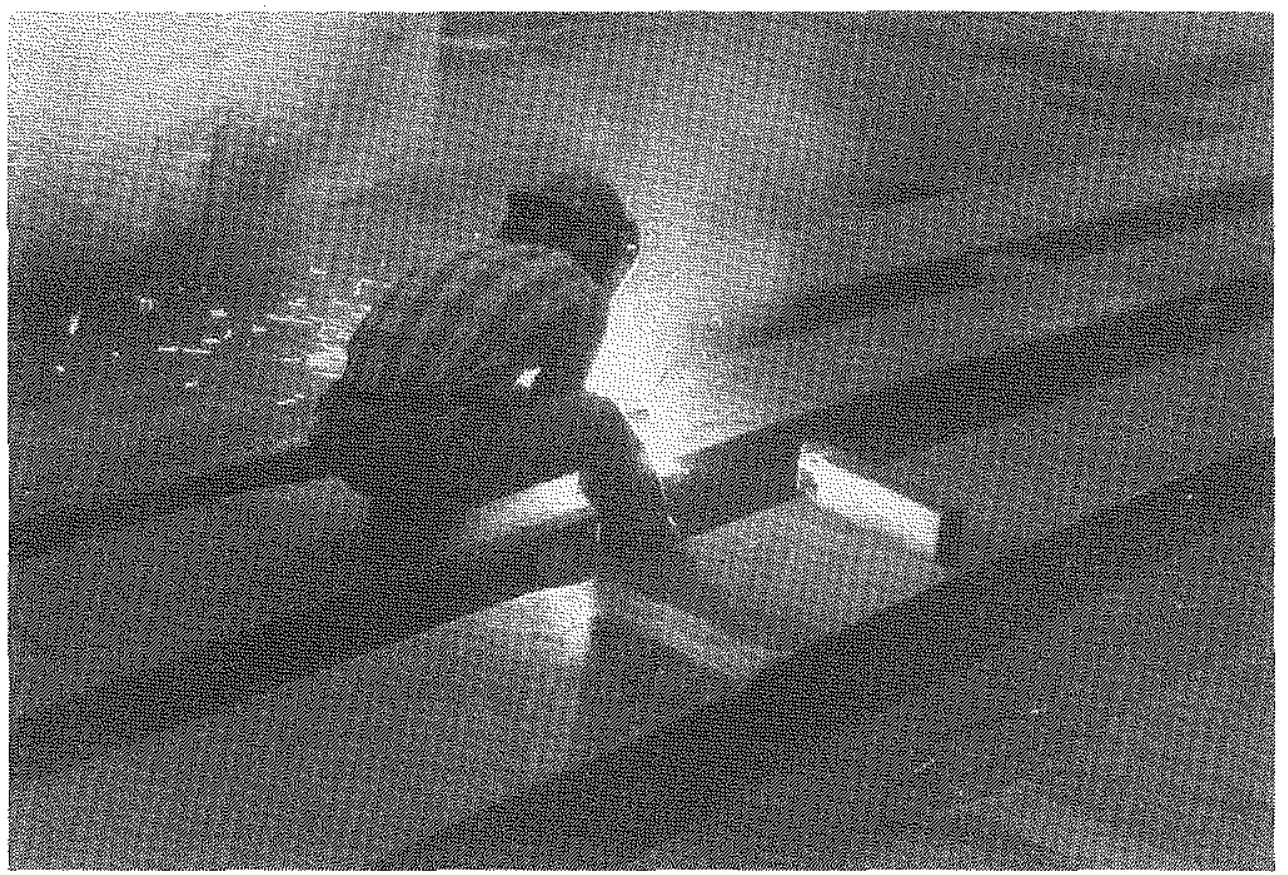

Figure 10. Carbon-Air Arc Backgouging on Back Side of a Flange Weld. 
testing was performed shortly after a weld was completed.

often, completed weldments were moved to an outside storage yard and in some cases were not inspected up to 30 days after the weld was completed. That delayed processing of AEWM report forms the technician had submitted to the shop QC personnel.

\section{PROGRESS OF AEWM TESTING}

In January the shop testing progressed slowly due primarily to the KTRP technician's unfamilfarity with the operations at High Steel. Initially, KTRP had obtained permission from two state highway agencies, Vermont and New York; to monitor their welds. However, in mid-January, it became apparent that access to welding operations of more highway agencies was necessary to perform a sufficient number of tests. Therefore, highway agencies of two additional states, Maryland and New Jersey, were contacted and permission was granted to monitor their welding operations.

Several problems restricted the number of tests performed early in the shop testing program.

High-temperature transducers necessary to monitor flange operations were not avallable during the first several months of testing. The shop routinely welded flanges routinely on the day shift. Web welding operations were conducted less frequently on any of three 8-hour work shifts. Shop scheduling made it difficult for the technician to determine when webs were being welded. On several occasions, the KTRP technician spent two shifts at the shop waiting on a web welding operation, only to have it completed during the next shift after he had left the shop.

Typically, it took from several hours to a half day to complete a web weld. In part, that was due to shop procedures. Also, High Steel did not pressure its welders to produce the welds at an accelerated pace.

By the end of February, shop monitoring improved and the technician was able to test 15-20 welds per month. In March, high-temperature transducers were acquired and applied on flanges. Some of that work was not successful and consumed some test time in unproductive monitoring operations.

In early June, it was determined that by the end of the scheduled shop operations, June 30,1987 , less than 100 welds would have been tested. Therefore, KTRP requested that the shop testing be extended four months through the end of october. That request was granted and the shop monitoring operations continued another four months with permission of High Steel. 
In early September, the high-temperature transducer problem was resolved. Both flange and web welds could be monitored, increasing the test output. By the end of the shop work, a total of 153 weldments had been tested. on October 29, the shop tests at High steel were terminated and KTRP personnel and equipment returned to Lexington, Kentucky, for final data analyses and report preparation.

\section{WELD PROCEDURE PREQUALIFICATION}

In July 1987, the Maryland Department of Transportation requested that the KTRP technician perform AE monitoring on a weld prequalification procedure being conducted at High Steel. The purpose of that test was to determine whether delayed (hydrogen-induced) cracking might occur in a particular weldment and if a wating period was necessary prior to conducting conventional nondestructive testing. Special flaw models that GARD had developed for post-weld monitoring and delayed cracking were obtained by KTRP. Those models were temporarily programmed into the AEWM and used during postweld monttoring of the test piece.

The initial prequalification test was unsuccessful. After the weld was completed and post-weld AE monitoring initiated, the KTRP technician left the shop. On returning the next morning, he found that the AEWM had been disconnected by shop personne1, thereby losing all data. A second prequalification test was performed. The test procedure required post-weld monitoring for a period of 96 hours. No post-weld cracking was detected by the AEWM, indicating that the weld configuration and test procedures were not susceptible to post-weld cracking. Therefore, production welds could be inspected immediately upon completion. That test resulted in the easing of inspection restrictions for the fabrication shop and a cost savings by reducing weldment handling. The test also demonstrated the long-term immunity of the AEWM to electrical noise in the shop. 


\section{TEST PROBLEEMS}

Several initial problems were experienced in the application of the hightemperature PAC RH15 transducers. In March, they were used in several flange tests. Unfortunately, the PAC transducers did not fit properly in the holddown receptacles that were originally designed for the larger AET transducers. Shims were employed to expand the diameter of the transducers and allow them to fit snugly into the receptacles. Shimming was achieved by wrapping electrical tape around the transducers and placing several washers into the receptacles to make up for the lack of height of PAC transducers compared to the AET units, During flange welding, temperatures on the transducer receptacles exceeded $400{ }^{\circ} \mathrm{F}$, which could be anticipated since the temperatures of the weldments sometimes exceeded $500{ }^{\circ} \mathrm{F}$. Unfortunately, the high temperatures caused the shim tape to melt. That allowed a transducer to twist inside its receptacle and uncouple from the weldment surface.

During several flange tests, transducers became uncoupled due to the shimming problem. Typically, the technician would notice the absence of $A E$ activity on the indicating lights of one channel of the AEWM. Unfortunately, that problem sometimes remained undetected until well into the progress of a weld pass, preventing the detection of acoustic emissions (or flaws). In one test, large slag inclusion was detected in a flange weld after that occurred. Inspection of the transducers revealed that one had separated from the weldment surface, invalidating the monitoring process.

During the initial flange tests, GARD personnel questioned whether the PAC transducers were suitable for use with the AEWM due to their high resonant frequency $(500 \mathrm{kHz})$. The required $\mathrm{AE}$ signal frequency for operation of the AEWM is around $200 \mathrm{kHz}$. The PAC transducers were shipped to the GARD laboratory in Niles, Illinois, and subjected to a hellum-jet (white-noise) source to determine their resonant frequencies. The transducers were found to contain resonant frequency peaks within the operating range of the AEWM and therefore, were satisfactory for use. Concurrently, properly fitting transducer receptacles were fabricated. The transducers and new receptacles were delivered to the KTRP technician in september 1987 and were used successfully thereafter (Figure 11 ).

Another problem was false AEWM indications that were termed "center hits." Early in the test program, AE indications were detected at locations centered on the transducer array. Typically, those "center hits" would occur when a welding operation was not in the center portion of a weld. 
At first, those false indications were attributed to broken tack welds. However, inspection of data from prior tests showed that many of those indications were encountered on the "B face" welds. "Center hits" could not related to that phenomena as the tack welds had been eliminated by backgouging on the "B face" prior to welding. For some time thereafter, that problem was attributed to flux-crushing noise. Occasionally, "center hits" would be detected in conjunction with other phenomena such as a welder sliding his seat along a plate or personnel walking on the weldment being monitored. It was thought that those actions crushed loose flux particles inducing the false $\mathrm{AE}$ indications. Another suspect source was a welder chipping slag as he deposited a weld (Figure 12). However, this did not prove to be a cause, as will be discussed later. These "center-hit" indications occurred almost as frequently as off-center "valid" or "unconfirmed" AE indications.

It was necessary to identify the cause of "center hits" and seek a remedy. It was hoped that they could be eliminated by a simple means such as a modification of the flaw-detection software. The KTRP principal investigator took the Pertec floppy disk recorder to the fabrication shop in September 1987. Along with GARD personnel, he instructed the KTRP technician in the operation of the AEWM in the "data-recording" mode. During that visit, efforts were made to create false "center hits" by crushing flux, fracturing fused slag with a chipping hammer, walking on the plate distant from the $\mathrm{AE}$ array, and a number of other fretting types of noise activity. The unit rejected all of those attempts as noise.

It was concluded the source of the "center hits" was probably "out-ofarray" activity that might be related to electric arcing between underlying stacked plates and the top plate being welded. Typically, a number of plates were beveled, fitted-up, tacked welded together, and stacked upon each other prior to welding. In some cases, the welding-machine ground wire was not attached directly to the plate being welded, but rather, to an underlying plate. Movement of a top plate might change its contact with underlying plates and possibly cause arcing. Arcing would create false "out-of-array" noise that could be classified as flaws by the AEWM.

AEWM tests were recorded on floppy disks in the "data-recording" mode for several weeks. Several examples of "center hits" and other "valid" and offcenter "unconfirmed". AE activity were recorded for comparisons. If simple solutions were to be obtained, it was felt that only a few examples of each type of indications would be needed to differentiate between them. Since the 


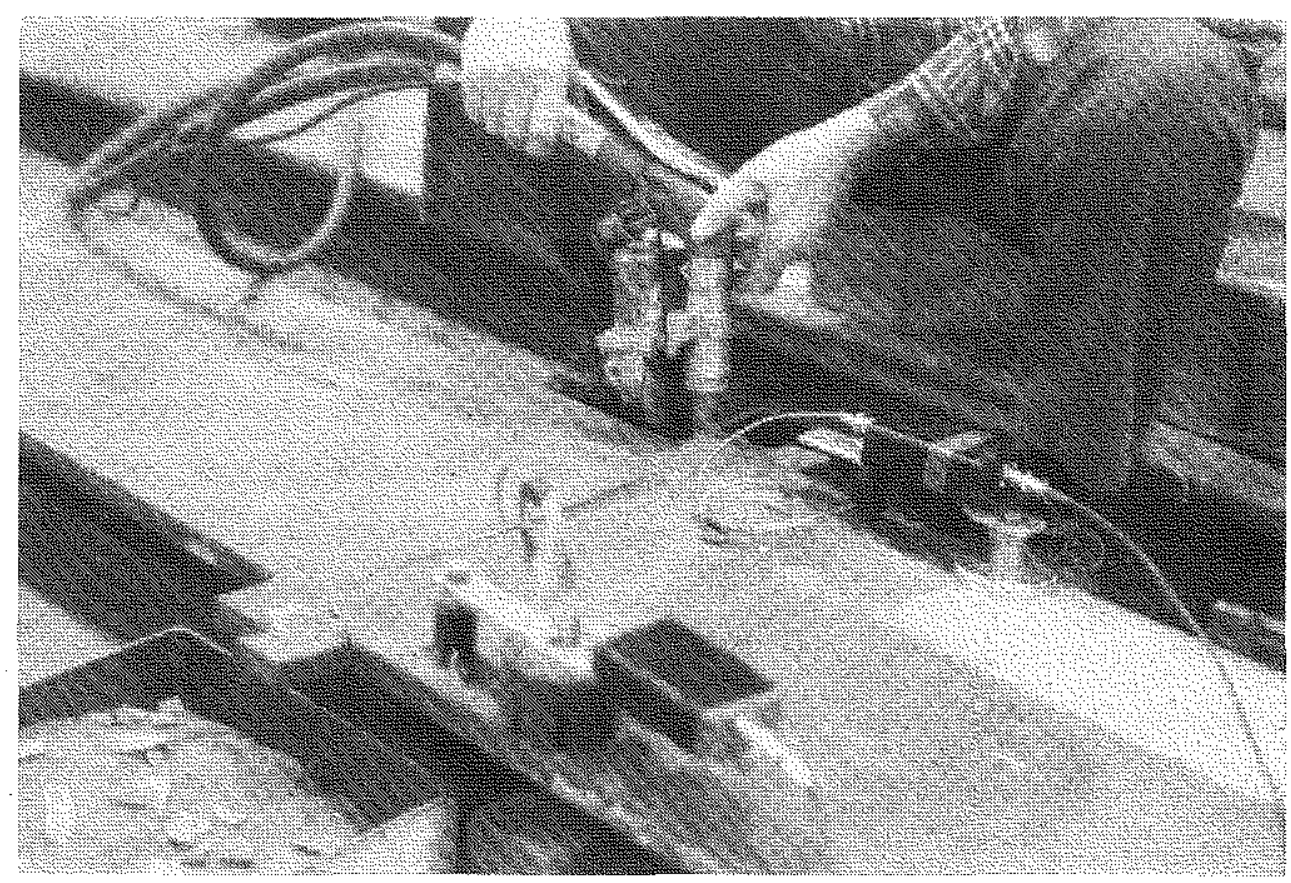

Figure 11. Depositing Weld on Flange (Note magnetic holddown assemblies that contain preamplifiers and transducers).

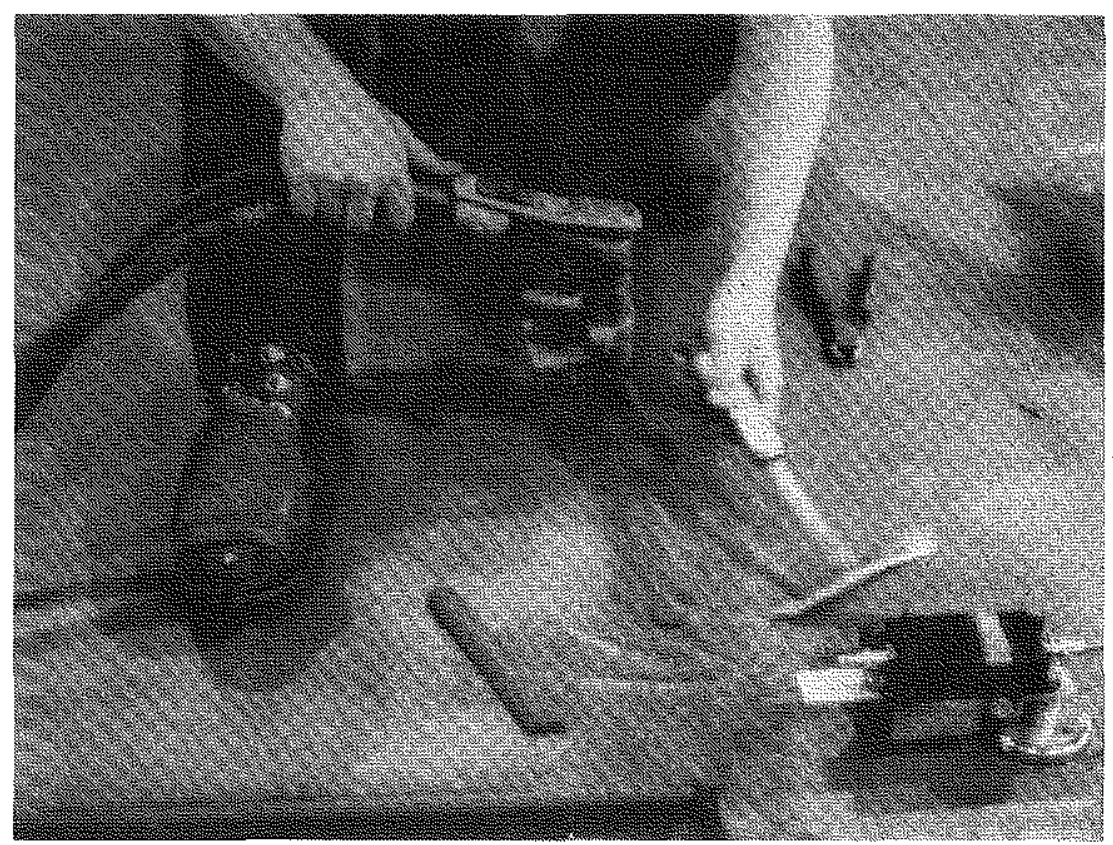

Figure 12. Welder Chipping Flux during Welding Operation. 
Pertec recorder was the last functioning unit available, its use was terminated after recording the desired AEWM indications and the unit was stored until the end of the field tests.

In June, dust problems caused the Microbee terminal to break down. Thereafter, an ADM 3A terminal was used for the monitoring tests. In August, 1t was accidentally knocked off the AEWM cart. The unit was quickly repaired and returned to the fabrication shop.

In July and early August, the AEWM began to malfunction due to dust. The unit contained small dust filters on the face of the instrument panel. However, it was not sealed tightly. Dust was able to enter the AEWM through the filters and cracks in the instrument cover. Eventually, some push-button controls and electric circultry began to operate erratically. That was remedied by blast cleaning the inside of the weld monitor with compressed air. Thereafter, the unit functioned properly, but required additional bi-weekly cleanings. Dust problems eventually affected the operation of the ADM $3 \mathrm{~A}$ terminal and caused it to occasionally malfunction. The AEWM and the terminal were subsequently covered at nights to prevent the entrance of excess dust. However, normal daily usage allowed considerable dust to enter the units and occasionally affect their operation.

\section{SUBMERGED-ARC WELDING AND FLAWS}

During previous testing at the Phoenix Steel Shop and in the course of this work, it was observed that submergedmarc welding operations are not inherently flaw-free. The number of flaws induced by submerged-arc welding did not appear to be related to the degree of automation nor, in this case, to the particular welding method employed at High Steel.

During the shop tests, approximately one of five weldments contained a flaw sometime during the welding operation (often during a root pass). This contrasted with both the shop $\mathrm{QC}$ and $\mathrm{QA}$ NDT results that revealed a low defect rate for completed butt welds.

\section{ROLE OF THE WELDER IN QUALITY CONTROL}

The difference between the initial high flaw rate experienced during welding and the low final weld-rejection rate is that a welder detects defects induced in the course of welding and repairs them prior to weld completion. In making repair decisions, a welder has little interaction with welding engineers or shop QC personnel. The fact that the final defect 
rejection rate is very low indicates this procedure is successful where good workmanship is stressed. In such shops, quality and defect prevention are emphasized. However, an unfavorable result is an obvious difference in productivity between welders.

Experlenced welders may better judge what welding situations result in defects. Also, they tend to have higher productivity with fewer problems than do inexperienced welders. Inexperfenced welders spend more time in weld preparation between passes than experienced welders (Figure 13). Also, inexperienced welders tend to be more cautious and spend more time inspecting their work.

In one instance, two experienced welders, who had greatly differing rates of production, were observed. One welder performed grinding operations at the end of every pass. The other performed the same welding operation, but did not extensively recondition welds between passes. The quality of the output for both welders was equivalent. But, the less-cautious welder produced significantly more work than his counterpart.

That variation in productivity occurs because a welder has no readily available criteria denoting either that a given weld pass is satisfactory or that it must be repaired. Presently, the only sure indication of weld quality is provided by nondestructive testing after the welding operation is completed. If a defect is present, a welder must make a repair. Since weld defects reflect poorly on a welder in a shop that stresses weld quality, he becomes overcautious.

Weld cost trends are based on historical performance data. Obviously, slow welders Increase the cost of welding. Although some welders have greater productivity than overly cautious welders, they produce equivalent quality welds and therefore, are more cost-effective than their slower counterparts. Weld costs based on the slow welders result in more expenstve bridges to highway agencies.

Unproductive periods occur during welding operations. Occasionally, a welder has to abstain from welding while a QC or QA inspector occupies his work station to perform conventional nondestructive testing on a completed weld. Another unproductive occurrence is a repair to remove a defect (Figure 14). A welder has to backgouge and grind the defective area prior to rewelding. Repair welds are usually carefully monitored by both QC and QA personnel. Oftentimes, preheating operations are required prior to making repair welds, further slowing the process. 


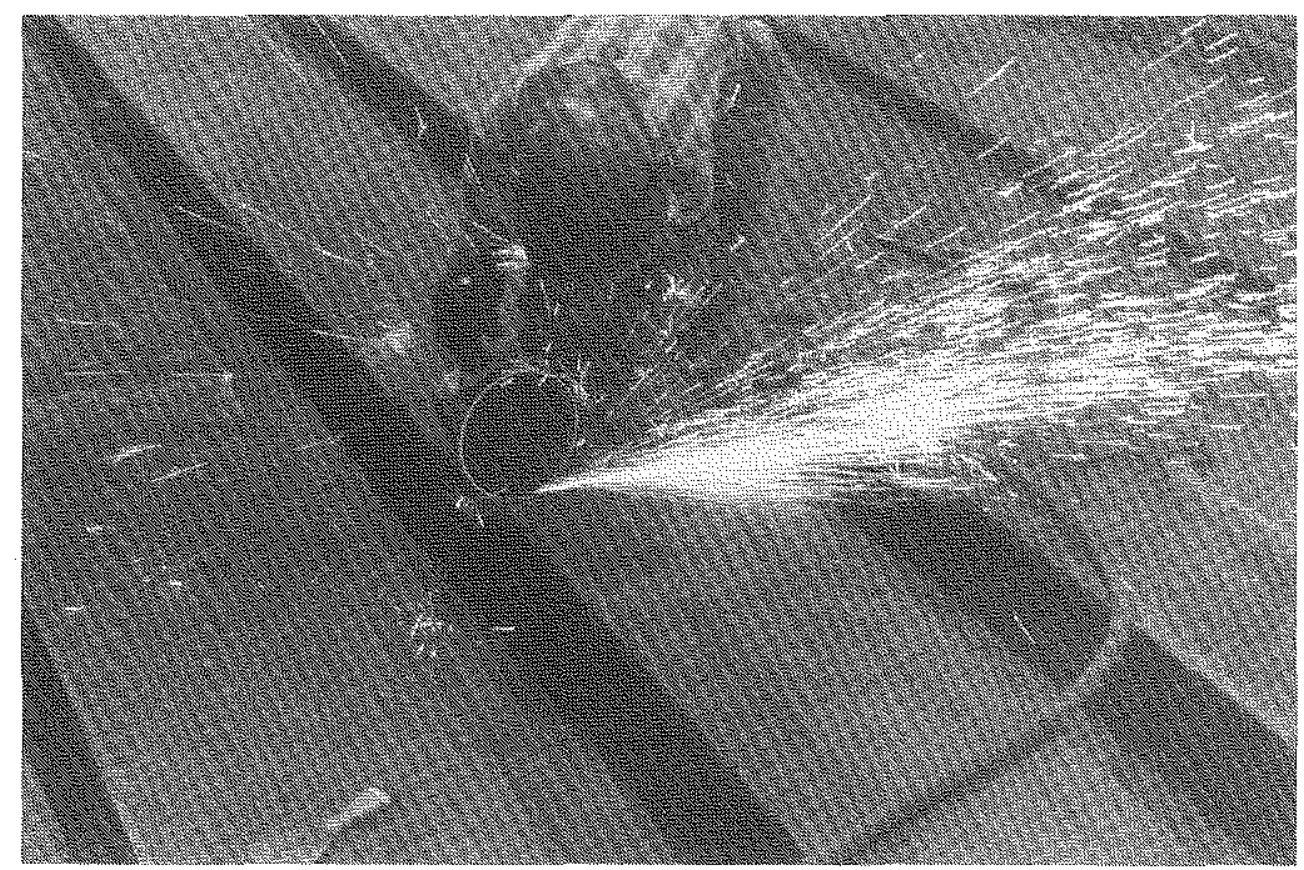

Figure 13. Grinding a Surface Blemish Prior to Depositing a Succeeding Weld Pass.

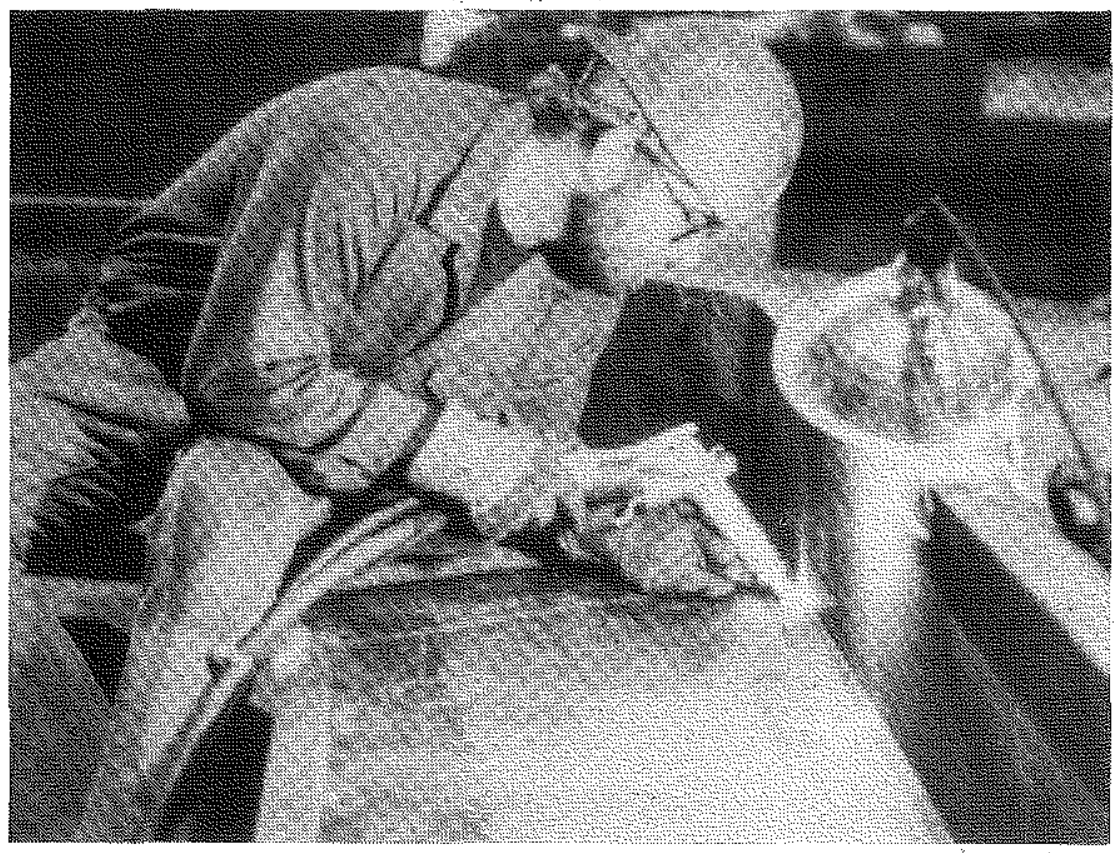

Figure 14. Manual Submerged-Arc Weld Repair of Large Weldment. 


\section{FLAWS ENCOUNTERED DURTNG TESTING}

During the shop tests, no major weld cracks were detected by visual inspection, conventional nondestructive testing, or AEWM monitoring. occasionally, small cracks, termed "crater cracks", would be detected that were inadvertently created when a weld was stopped due to loss of flux or welding wire. During work at Phoenix steel, prior to this study, a crack was detected by the AEWM. That crack was confirmed by conventional ultrasonic testing and ensuing repair work.

The most persistent type of flaws are slag inclusions (Figures 15 and 16). Oftentimes, slag inclusions are created during the deposition of a root pass or by formation of what is termed a "ro11." "Ro11s" are caused by the improper positioning of the welding gun to one side of a groove bevel during welding. That causes molten weld metal to roll over the flux during the deposition, possibly trapping some slag (Figure 17). "Rolls" associated with slag inclusions were readily detected by the AEWM (Figure 18). Sometimes, rolls did not create slag inclusions. In those cases, the AEWM did not indicate flaws. When visually inspected, both cases appear similar. Typically, welders ground "rolls" out prior to depositing the next weld pass. However, several welders just welded over them.

Occasionally, the AEWM detected welding irregularities that might affect the quality of a completed weld. Typically, those irregularities were related to simple problems such as loss of flux (Figure 19) or depletion of welding wire (Figure 20). On several occastons, poor weldment fit-up caused burnthroughs or slag-related problems on the root pass (Figure 21).

In several instances, small porosity was missed by the AEWM. However, it was subsequently detected by visual inspection. The porosity was apparent as small dimpled indications on the surface of the completed weld. However, none of those were severe enough to warrant repairs. 


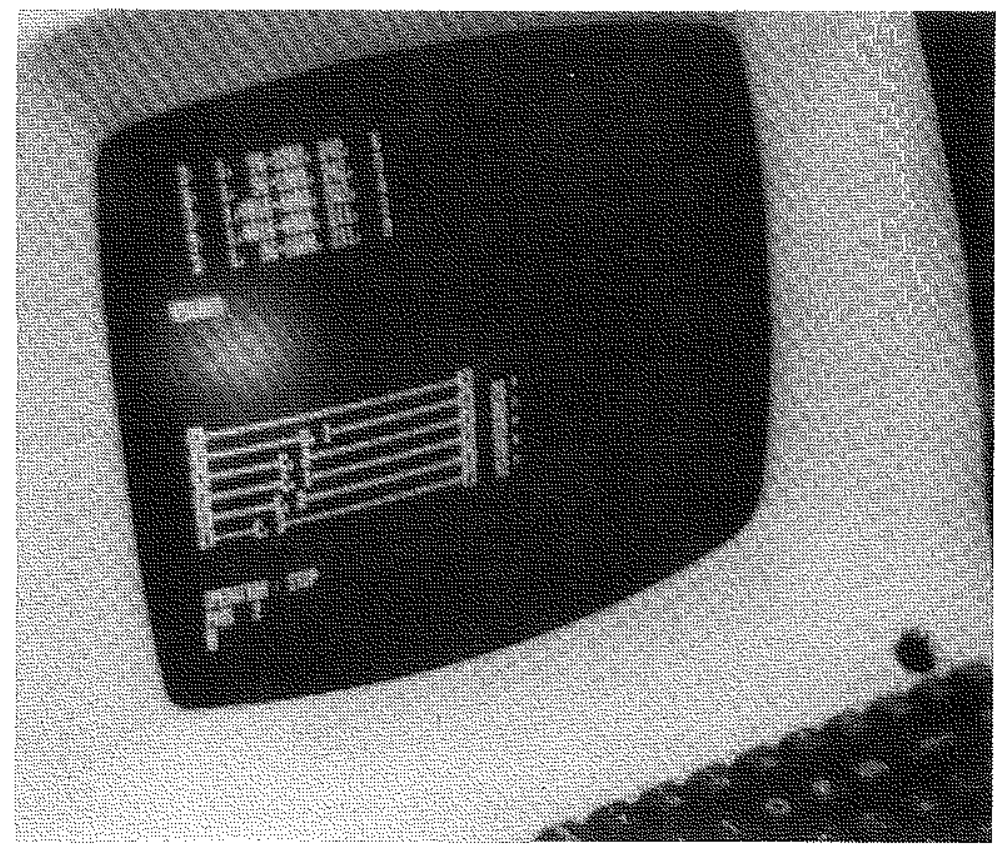

Figure 15. AEWM Flaw Indication from Web Welding Operation.

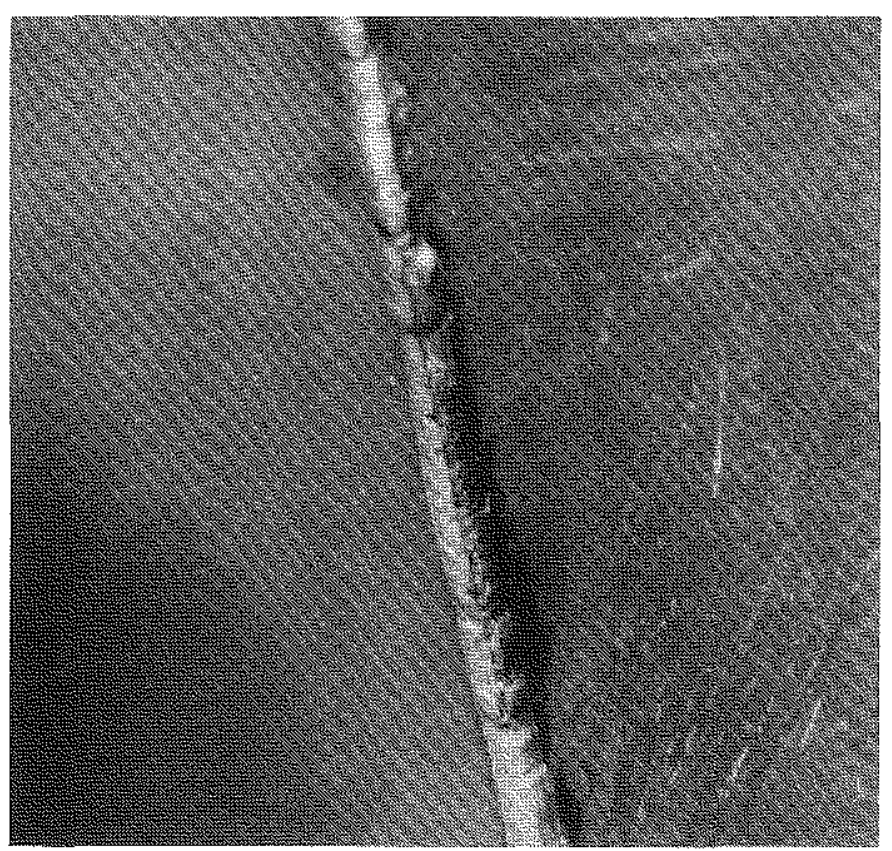

Figure 16. Slag Stringer (Figure 15) Revealed after Backgouging. 

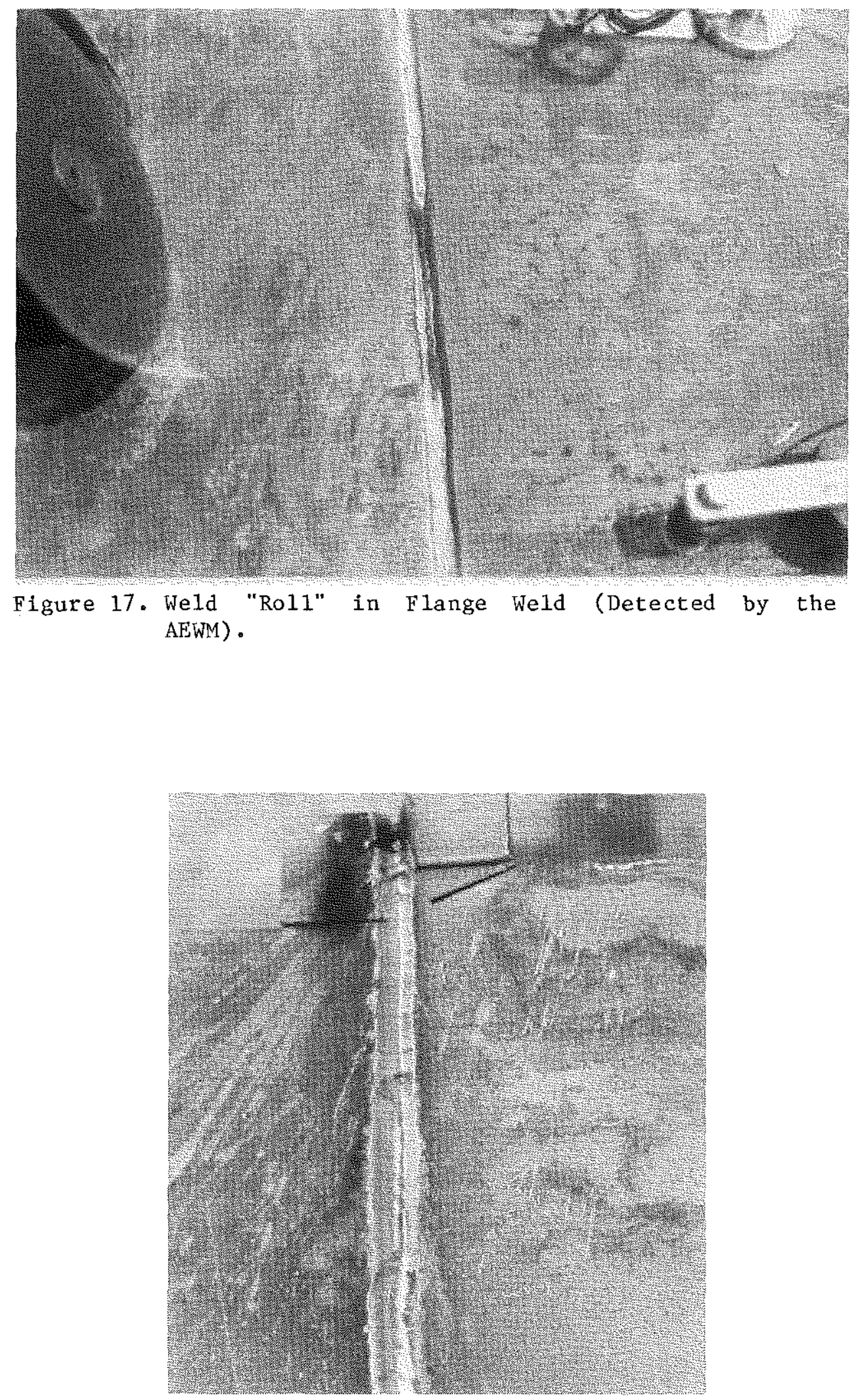

Figure 18. Slag Inclusion in Weld (Figure 17) Revealed by Backgouging. 


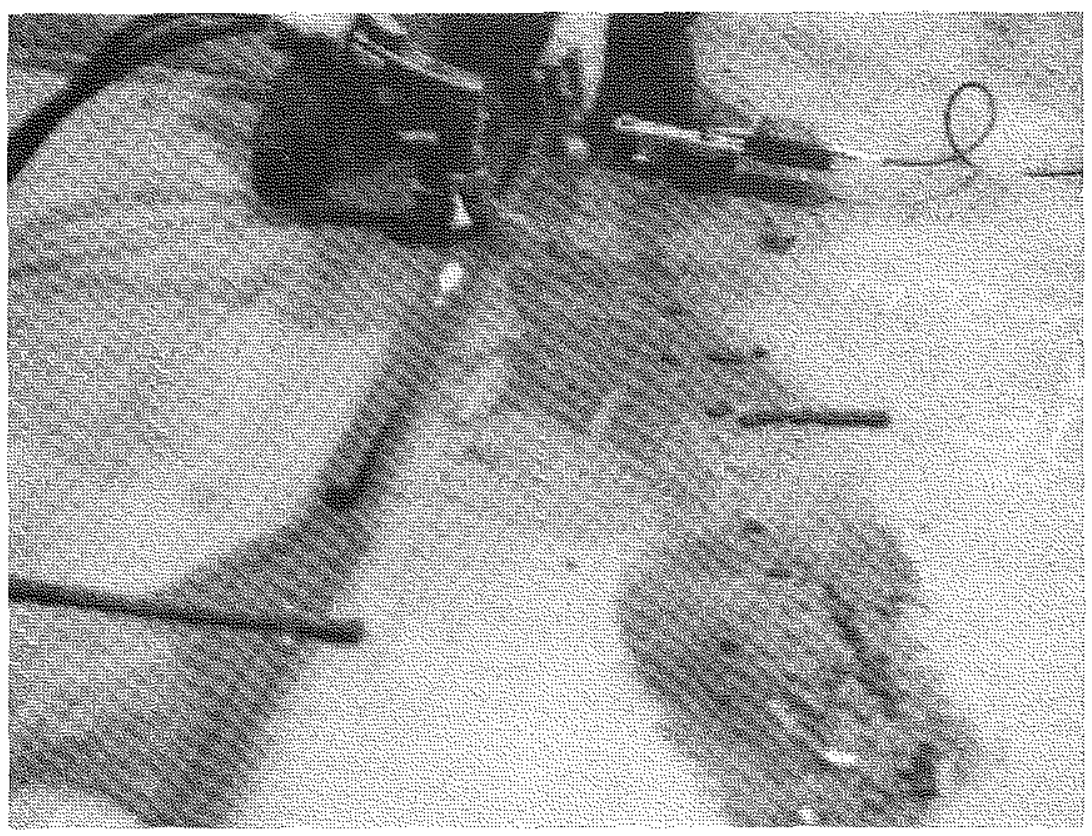

Figure 19. Weld Irregularity Caused by Temporary Loss of Flux.

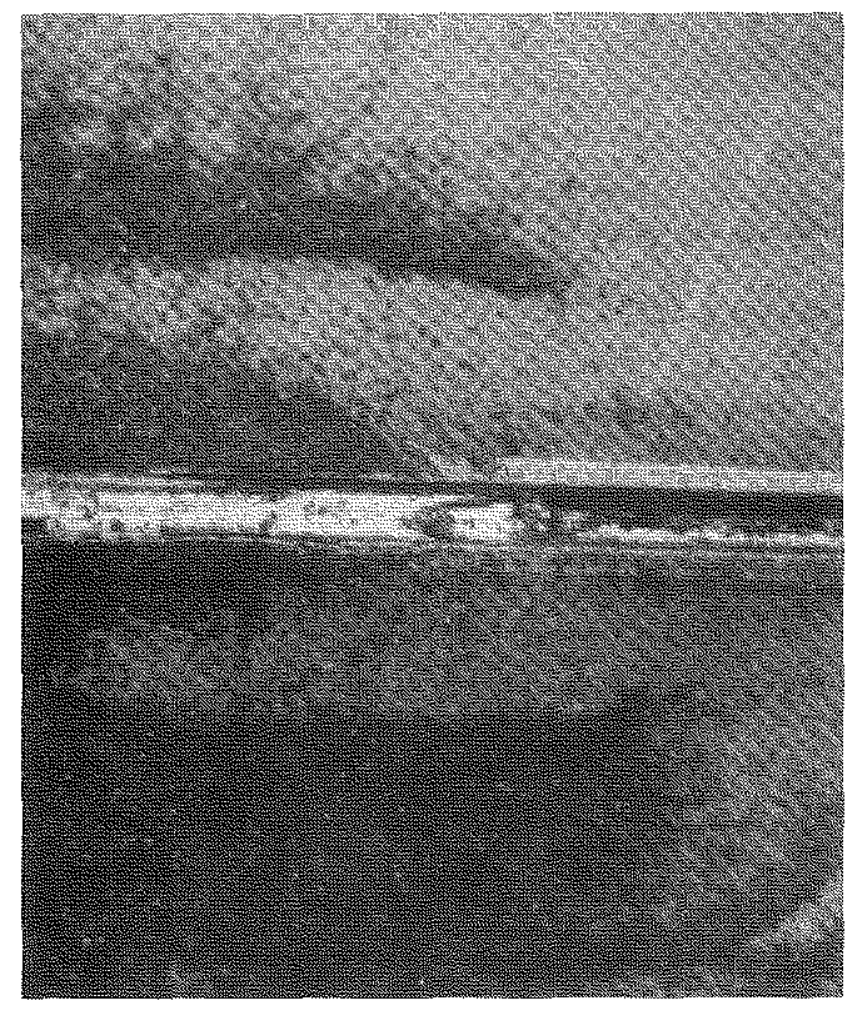

Figure 20. Flaw at Weld Termination (S1ag and Porosity) Detected by AEWM. 


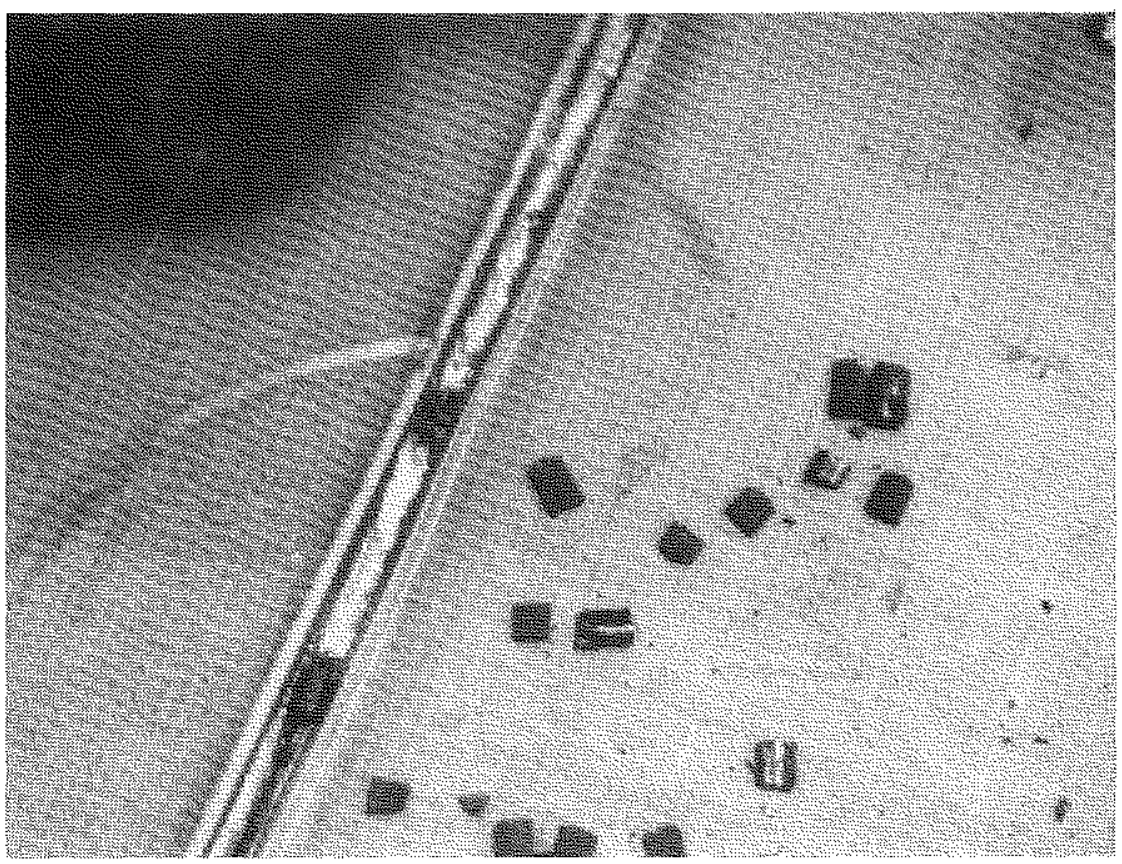

Figure 21. Trapped Surface Weld Slag Detected by AEWlM during Root Pass Weld and Subsequently Repaired by Grinding. 



\section{AEWM TEST RESULTS}

A tabulation of the AEWM test results is provided in Table 1. Data summaries for the AEWM fabrication-shop testing are shown in Table 2 (webs) and Table 3 (flanges). A substantial quantity of welding was inspected. A total of 736.2 feet of completed web and flange welds were monitored with the AEWM. This corresponds to 4,935 lineal feet of deposited weld. A total of 1,322 weld passes were monitored during the shop testing program, which ran from January 6 to October 29, 1987. The average length of web welds monitored was 70.9 inches and the average length of flange welds monitored was 19.3 Inches.

\section{AEWM FLAW DETECTION PERFORMANCE}

A total of 263 AEWM indications was encountered during those tests. The indications were categorized as "valid" flaw indications, "center hits," and "unconfirmed" (off-center) indications. "Valid" indications were those detected and located by the AEWM and correlated with flaws visible on the weld, surface irregularities in the welding process, or indications confirmed by conventional nondestructive testing (regardless of code-rated severity). "Center hits" were those $\mathrm{AE}$ indications detected within several inches of the center of the transducer array (weld) that were not verified by other means. "Unconfirmed" indications were off-center $\mathrm{AE}$ activity also not confirmed visually or by follow-up NDT inspections.

"Valid" flaw indications accounted for approximately 13 percent of the total AE flaw activity detected by the AEWM in both the web and flange tests. Twenty-five "valid" flaw indications were detected in web welds and 10 were detected in flange welds. False "center hits" accounted for approximately half of all the $A E$ indications detected by the AEWM, including 47.1 percent of the $\mathrm{AE}$ activity for webs and 62.5 percent for flanges. The total number of "unconfirmed" indications was approximately 39 percent of the total for the web welds and 23.6 percent for flange welds.

It is important to note that the unit did not experience any undercalls (missed defects) including visually detected flaws encountered during the welding operation and repaired, or flaws detected by conventional nondestructive testing of a completed weldment. Three "valid" AEWM indications were confirmed by conventional nondestructive testing 
TAELE 1. AEMM FABRICATION SHOP TEST DATA

\begin{tabular}{|c|c|c|c|c|c|c|c|c|c|c|c|c|c|c|c|c|c|c|c|}
\hline $\begin{array}{l}\text { WELD } \\
\text { NO. }\end{array}$ & $\begin{array}{l}\text { TEST } \\
\text { DATE }\end{array}$ & $\begin{array}{l}\text { WELD } \\
\text { MATL. }\end{array}$ & $\begin{array}{l}\text { WIRE/ } \\
\text { FL.LX }\end{array}$ & $\begin{array}{l}\text { WHD } \\
\text { WOLT }\end{array}$ & $\begin{array}{l}\text { WEL } \\
\text { SPD. } \\
\text { (IPM) }\end{array}$ & $\begin{array}{l}\text { PRE- } \\
\text { IEAT } \\
\text { ( }{ }^{\circ} \text { F) }\end{array}$ & $\begin{array}{l}\text { MATL } \\
\text { THK. } \\
\text { (IN.) }\end{array}$ & $\begin{array}{l}\text { WEE D } \\
\text { LG. } \\
\text { (IN.) }\end{array}$ & $\begin{array}{l}\text { WEL } \\
\text { PASSES }\end{array}$ & $\begin{array}{l}\text { TOT.LG. } \\
\text { INSP. } \\
\text { (IN.) }\end{array}$ & $\begin{array}{l}\text { AEWM } \\
\text { GAIN } \\
\text { (dB) }\end{array}$ & $\begin{array}{c}\text { YALID } \\
\text { AEM } \\
\text { INDIC. }\end{array}$ & $\begin{array}{l}\text { CONV. } \\
\text { NOT. }\end{array}$ & $\begin{array}{l}\text { NDT } \\
\text { TYPE }\end{array}$ & $\begin{array}{l}\text { AEMM } \\
\text { CTR. } \\
\text { HITS }\end{array}$ & $\begin{array}{l}\text { CTR.HIT } \\
\text { CATEGORY } 0\end{array}$ & $\begin{array}{l}\text { AEMM } \\
\text { OVERCALL }\end{array}$ & $\begin{array}{l}\text { OVERCALH } \\
\text { CATEGORY }\end{array}$ & IISCUSSION AND COMMENTS \\
\hline 1 & $1 / 15$ & 588 & $1.61 / x \times \times 10$ & 35 & 100 & & $11 / 16$ & 71 & 6 & 426 & $53-53$ & 1 & 0 & RAD & 5 & $c, 1(3) ; c, 2 ; u, 3$ & 1 & u, 2๗3 & $\begin{array}{l}1 \text { VISJALLY COF. SLAG } \\
\text { C,5 } 5 \text { 50" REPAIRED }\end{array}$ \\
\hline 2 & $1 / 19$ & 588 & $\mathrm{~L} 61 / x \times \times 10$ & 33 & 87 & & $1 / 2$ & 74 & 4 & 296 & $55-59$ & 0 & 0 & RAD & 2 & $c, 1 ; u, 3$ & 0 & & \\
\hline 3 & $1 / 22$ & 588 & $\mathrm{~L} 61 / x \times \times 10$ & 34 & 88 & 200 & 1 & 110 & 13 & 1430 & 59-ฒ & 0 & 0 & RAD & 1 & $c, 2$ & 0 & & DUE TO CHIPPING \\
\hline 4 & $1 / 28$ & 588 & L61/ /0XX10 & 35 & 100 & 200 & 1 & 110 & 10 & $\$ 100$ & $57-59$ & 0 & 0 & RAD & 15 & $c, 2-6 ; u, 1-2$ & 0 & & DUE TO CHIPPING \\
\hline 5 & $2 / 02$ & 588 & L61/xxx10 & 32 & 86 & & 1 & 70 & 5 & 350 & $55-59$ & 0 & 0 & $R A D$ & 6 & $c, 1-4 ; u, 1-4$ & 0 & & \\
\hline 6 & $2 / 02$ & 588 & L61/ $x \times \times 10$ & 32 & 85 & & $11 / 16$ & 70 & 5 & 350 & $53-55$ & 0 & 0 & RAD & 3 & $c, 2 ; u, 3 ; u, 6$ & 1 & $c, 2 \Subset 30^{n}$ & \\
\hline 7 & $2 / 05$ & 598 & $161 / x \times \times 10$ & 32 & 78 & & $3 / 8$ & 52 & 5 & 260 & $53-53$ & 1 & 0 & RAD & 0 & & 0 & & $\begin{array}{l}1 \text { VISJALY CON. ROLL } \\
c, 4 \text { O } 34^{*} \text { REPAIRED }\end{array}$ \\
\hline 8 & $2 / 05$ & 588 & L61/ $x \times x 10$ & 32 & 84 & & $1 / 2$ & 52 & 4 & 208 & $53-55$ & 0 & 0 & RAD & 0 & & 0 & & \\
\hline 9 & $2 / 09$ & 588 & $1.61 / x \times \times 10$ & 32 & 77 & & $1 / 2$ & 53 & 5 & 265 & $53-55$ & 1 & 1 & $R A D$ & 0 & $c, 6$ & 0 & & $\begin{array}{l}\text { SEF NOTE } 1 \text { COFTIRMED } \\
\text { BY RADIOGRAPHY }\end{array}$ \\
\hline 10 & $2 / 09$ & 588 & L61/XXX10 & 32 & 77 & & $1 / 2-3 / 8$ & 52 & 7 & 364 & $53-55$ & 3 & 0 & RAD & 2 & $u, 2 ; u, 3$ & 0 & & $\begin{array}{l}3 \text { VISLAUIY COAE. } \\
\text { SEE NOTE } 2\end{array}$ \\
\hline 11 & $2 / 09$ & 588 & $161 / x \times \times 10$ & 34 & 84 & & $1 / 2-3 / 8$ & 52 & 4 & 208 & $53-55$ & 0 & 0 & RAD & 0 & & 0 & & \\
\hline 12 & $2 / 09$ & 588 & {$[61 / x \times X 10$} & 34 & 84 & & $1 / 2-3 / 8$ & 54 & 5 & 270 & $53-55$ & 0 & 0 & RAD & 1 & $u, 2$ & 3 & $\begin{array}{l}u, 1 \oplus 32^{n} \\
u, 3 \oplus 14^{*} \\
u, 3 \odot 36^{n}\end{array}$ & \\
\hline 13 & $2 / 09$ & 588 & L61/N0X10 & 34 & 84 & & $3 / 8$ & 52 & 4 & 208 & $53-55$ & 0 & 0 & RAD & 0 & & 0 & & \\
\hline 14 & $2 / 09$ & 588 & $1.61 / x \times x 10$ & 34 & 84 & & $1 / 2$ & 54 & 4 & 216 & $53-55$ & 0 & 0 & RAD & 2 & $u, 1 ; c, 1$ & 1 & & $\begin{array}{l}\text { WEID OPERATOR HAD JOG IN } \\
\text { PASS c,2828" }\end{array}$ \\
\hline 15 & $2 / 10$ & 588 & $L 61 / X \times X 10$ & 32 & 84 & & $1 / 2$ & 53 & 4 & 212 & $53-57$ & 0 & 0 & RAD & 2 & $u, 1 ; c, 5$ & 0 & & \\
\hline 16 & $2 / 10$ & 588 & $161 / x \times \times 10$ & 32 & 77 & & $3 / 8$ & 50 & 4 & 200 & $53-57$ & 3 & 0 & RAD & 1 & $c, 2$ & 0 & & $\begin{array}{l}3 \text { VISUAL. CONF. SEE } \\
\text { NOTE } 3 \text { WELED OVER }\end{array}$ \\
\hline 17 & $2 / 10$ & 598 & $161 / x \times 10$ & 32 & 84 & & $1 / 2$ & 53 & 5 & 265 & $53-57$ & 1 & 0 & $R A D$ & 1 & $c, 4$ & 1 & & $\begin{array}{l}2 \text { VISUAL CONF. SEE } \\
\text { NOTE } 4 \text { REPAIRED }\end{array}$ \\
\hline 18 & $2 / 10$ & 588 & L.61 $/ X X \times 10$ & 34 & 84 & & $1 / 2$ & 51 & 4 & 204 & $53-57$ & 0 & 0 & RAD & 1 & $c, 3$ & 0 & & \\
\hline 19 & $2 / 10$ & 588 & $L 61 / x \times \times 10$ & 34 & 84 & & $1 / 2$ & 53 & 4 & 212 & $53-57$ & 0 & 0 & RAD & 1 & $c, 1$ & 2 & $\begin{array}{l}c, 1 \Subset 2^{*} \\
u, 5 \circledast 32^{\prime \prime}\end{array}$ & $\begin{array}{l}2 \text { HITS AT SANE LOCATION } \\
\text { OFF CENTER }\end{array}$ \\
\hline 20 & $2 / 11$ & 588 & $161 / x \times \times 10$ & 32.4 & 88 & & $5 / 8$ & 68 & 5 & 340 & $55-57$ & 1 & 0 & RADETT & 1 & $c ; 2032^{\prime \prime}$ & 0 & & $\begin{array}{l}1 \text { YISUALYY COAF. SLAG (ROLL) } \\
c, 2 \text {, }\end{array}$ \\
\hline
\end{tabular}

1 AEMM HAD ONE CENTER HIT c, 6E2 $4 "$ : HIGH STEE FOUND SLAG IN FIRST $16^{\prime \prime}$

2 PORSITY u,6034", RQLLS u,3624", u,1640" DUE TO FLUX FEEDING PROBLEMS: ALLL REPAIRED

3 PIN-HOLE POROSITY u,7@8", $c, 3 \notin \infty$ ", $c, 3 \% 4$ ": WELDED OVER

4 CRATER/FISHEYE c,4036"; POOR FIT-UP MADE WELD RDLGH, POSSIQLE ROOT AREA ACTIVITY c,4GQO": ALL REPAIRED 
TABLE 1. AEMM FABRICATION SHP TEST DATA (CONTINJE)

\begin{tabular}{|c|c|c|c|c|c|c|c|c|c|c|c|c|c|c|c|c|c|c|c|}
\hline $\begin{array}{l}\text { WELD } \\
\text { NO. }\end{array}$ & $\begin{array}{l}\text { TEST } \\
\text { DATE }\end{array}$ & $\begin{array}{l}\text { WELD } \\
\text { MATL. }\end{array}$ & $\begin{array}{l}\text { WIRE/ } \\
\text { FLUX }\end{array}$ & $\begin{array}{l}\text { WE.D } \\
\text { VQT }\end{array}$ & $\begin{array}{l}\text { WED } \\
\text { SPD. } \\
\text { (IPY) }\end{array}$ & $\begin{array}{l}\text { PRE- } \\
\text { FAT } \\
\text { ("F) }\end{array}$ & $\begin{array}{l}\text { MATL } \\
\text { THK. } \\
\text { (IN.) }\end{array}$ & $\begin{array}{l}\text { WELD } \\
\text { LG. } \\
\text { (IN.) }\end{array}$ & $\begin{array}{l}\text { IELD } \\
\text { PASSES }\end{array}$ & $\begin{array}{l}\text { TUT LG. } \\
\text { INSP. } \\
\text { \{IN.) }\end{array}$ & $\begin{array}{l}\text { AEMM } \\
\text { GAIN } \\
\text { (dB) }\end{array}$ & $\begin{array}{l}\text { VALID } \\
\text { AEMM } \\
\text { INDIC. }\end{array}$ & $\begin{array}{l}\text { CON. } \\
\text { NOT. }\end{array}$ & $\begin{array}{l}\text { NDT } \\
\text { TYPE }\end{array}$ & $\begin{array}{l}\text { AEMM } \\
\text { CTR. } \\
\text { HITS }\end{array}$ & $\begin{array}{l}\text { CTR.HIT } \\
\text { CATEGORY O }\end{array}$ & $\begin{array}{l}\text { AEMM } \\
\text { OVERCALL }\end{array}$ & $\begin{array}{l}\text { OVERCAIL } \\
\text { CATEGORY }\end{array}$ & DISCUSSION AND COMERTS \\
\hline 21 & $3 / 04$ & 588 & $161 / x \times \times 10$ & 32.7 & 92 & & $3 / 4$ & 108 & 6 & 648 & $55-57$ & 0 & 0 & RAD\&UT & 6 & $\begin{array}{c}c, 1(3) ; u, 2 ; \\
c, 3(2)\end{array}$ & 0 & & 더IPPING CAUSED FALSE HITS \\
\hline 22 & $3 / 05$ & 36 & $161 / 860$ & 32.5 & 83 & & $5 / 8$ & 66 & 4 & 284 & $62-62$ & 0 & 0 & RAD & 0 & 0 & 0 & & \\
\hline 23 & $3 / 08$ & 36 & $\mathrm{~L} 61 / \mathrm{x} \times \times 10$ & 32.5 & 84 & & $5 / 8$ & 62 & 4 & 248 & $02-62$ & 0 & 0 & $\mathrm{RAD}$ & 1 & บ.2œ30" & 1 & & CHIPPING POSSIBLE SORRE \\
\hline 24 & $3 / 09$ & 588 & $L 61 / x \times \times 10$ & 32.2 & 83 & & $11 / 16$ & 90 & 8 & 720 & $55-55$ & 0 & 0 & $\mathrm{RAD}$ & 0 & 0 & 4 & $\begin{array}{l}c, 2 ; u, 2 \notin 027^{\prime \prime} \\
c, 2-3 \in 22^{\prime \prime}\end{array}$ & CHIPPING POSSIBLE SOURCE \\
\hline 25 & $3 / 10$ & 588 & $L 61 / \propto X \times 10$ & 32.2 & 83 & & $11 / 16$ & 89 & 8 & 712 & $53-53$ & 0 & 0 & $R A D$ & 0 & 0 & 2 & $\begin{array}{l}u, 40688^{\prime \prime} \\
u, 4070^{n}\end{array}$ & \\
\hline 26 & $3 / 10$ & 588 & $261 / x \times \times 10$ & 34.6 & 93 & 350 & $21 / 4$ & 24 & 40 & 960 & $68-68$ & 0 & 0 & RAD & 1 & $c, 3630 "$ & 0 & & FLANGE \\
\hline 27 & $3 / 12$ & 588 & $261 / x \times x 10$ & 34.6 & 93 & & $21 / 4$ & 24 & 37 & 888 & $78-78$ & 0 & 0 & RAD & 0 & 0 & 0 & & \\
\hline 28 & $3 / 16$ & 572 & L61/860 & 33.4 & 92 & & $3 / 4$ & 110 & 6 & 660 & $59-59$ & 0 & 0 & RAD\&IT & 7 & $c, 1-5 ; u, 1(4)$ & 0 & & \\
\hline 29 & $3 / 17$ & 572 & $\mathrm{~L} 61 / 860$ & 34.1 & 92 & 300 & $31 / 4-13 / 4$ & 24 & 37 & 888 & $72-72$ & 0 & 0 & RAD\&ST & 0 & 0 & 1 & $c, 4022^{n}$ & FLANGE \\
\hline 30 & $3 / 17$ & 572 & $161 / 860$ & 34.1 & 92 & 300 & $31 / 4-13 / 4$ & 24 & 31 & 744 & $61-61$ & 0 & 0 & RADUT & 4 & $u, 1(2) ; u, 2-4$ & 0 & & FLANEE \\
\hline 31 & $3 / 18$ & 572 & L61/860 & 33.6 & 84 & & $5 / 8$ & 118 & 7 & 826 & $59-59$ & 0 & 0 & PADENT & 0 & 0 & 4 & 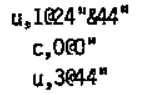 & $\begin{array}{l}\text { CHIPPING CAUSED } u, 1 \& c, 0 ; u, 1 \\
\text { ON ROOT PASS }\end{array}$ \\
\hline 32 & $3 / 19$ & 572 & $161 / 860$ & 33.6 & 85 & & $5 / 8$ & 116 & 5 & 580 & $59-59$ & 0 & 0 & RAD@T & 0 & 0 & 1 & u, 1 et2" & u,1 ON ROOT PASS \\
\hline 33 & $1 / 15$ & 588 & $\mathrm{L61/X \times X10}$ & 33.0 & 85 & & $11 / 16$ & 71 & 6 & 426 & $53-59$ & 0 & 0 & RAD & 4 & $c, 2-4 ; u, 1-6$ & 3 & $\begin{array}{l}c, 2016^{\prime \prime} \\
u, 2940^{\prime \prime}\end{array}$ & DJE TO CHPPING \\
\hline 34 & $1 / 08$ & 588 & $261 / 2 \times x \times 10$ & 33.1 & 84 & & 1 & 82 & 6 & 492 & $55-55$ & 0 & 0 & $\mathrm{R} \cap$ & 1 & $c, 3638^{n}$ & 0 & & \\
\hline 35 & $1 / 09$ & 588 & L61/860 & 33.5 & 85 & & $3 / 4$ & 81 & 6 & 486 & $53-53$ & 1 & 0 & RAD & 1 & u, 2৫3:" & 1 & & $\begin{array}{l}1 \text { YISJALYY OONF. SLAG } c, 7048^{n} \\
\text { REPAIRED }\end{array}$ \\
\hline 36 & $1 / 13$ & 588 & L61 $100 \times 10$ & 34.4 & 94 & & 1 & 106 & 4 & 424 & $53-57$ & 0 & 0 & RAD & 1 & $c, 4650^{n}$ & 0 & & \\
\hline 37 & $3 / 23$ & 588 & $L 61 / x \times x 10$ & 31.9 & 84 & & $9 / 16$ & 77 & 5 & 385 & $57-57$ & 0 & 0 & ROO\&T & 3 & $c, 2 ; u, 3-4$ & 4 & $\begin{array}{l}u, 2(2) \\
c, 1-4\end{array}$ & \\
\hline 38 & $3 / 24$ & 572 & $\mathrm{~L} 6 \mathrm{l} / 860$ & 33.7 & 86 & & $9 / 16$ & 77 & 5 & 385 & $57-57$ & 0 & 0 & RAD\&T & 0 & & 0 & & \\
\hline 39 & $3 / 26$ & 588 & $L 61 / x \times \times 10$ & 31.6 & 87 & & $1 / 2$ & 69 & 6 & 414 & $55-55$ & 0 & 0 & RAD & 0 & & 1 & $u, 3628 "$ & \\
\hline 40 & $4 / 07$ & 588 & $261 / x \times x 10$ & 34.6 & 96 & 200 & $13 / 4-1$ & $20-18$ & 14 & 380 & $57-57$ & 6 & 0 & RADथT & 1 & u,1є32" & 1 & $c, 4042$ & SEE NOTE 1 \\
\hline
\end{tabular}

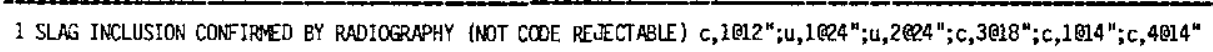


TABLE 1. AEMM FABR ICATION SHOP TEST DATA (CONTMNE)

\begin{tabular}{|c|c|c|c|c|c|c|c|c|c|c|c|c|c|c|c|c|c|c|c|}
\hline $\begin{array}{l}\text { WELD } \\
\text { NO. }\end{array}$ & $\begin{array}{l}\text { TEST } \\
\text { DATE }\end{array}$ & $\begin{array}{l}\text { MAL } \\
\text { MATL }\end{array}$ & $\begin{array}{l}\text { WIREI } \\
\text { FLLX }\end{array}$ & $\begin{array}{l}\text { welo } \\
\text { vOLT }\end{array}$ & $\begin{array}{l}\text { WELD } \\
\text { SPD. } \\
\text { (IPM) }\end{array}$ & $\begin{array}{l}\text { PRE- } \\
\text { IEAT } \\
\left({ }^{\circ} \mathrm{F}\right)\end{array}$ & $\begin{array}{l}\text { MATL } \\
\text { TH. } \\
\text { (IN.) }\end{array}$ & $\begin{array}{l}\text { YHD } \\
\text { LG. } \\
\text { (IN.) }\end{array}$ & $\begin{array}{l}\text { WELD } \\
\text { PASSES }\end{array}$ & $\begin{array}{l}\text { TOT.LG. } \\
\text { INSP. } \\
\text { (IN.) }\end{array}$ & $\begin{array}{l}\text { AEAM } \\
\text { GAIN } \\
\text { (dB) }\end{array}$ & $\begin{array}{l}\text { VALID } \\
\text { AEMM } \\
\text { INDIC. }\end{array}$ & $\begin{array}{l}\text { CONY. } \\
\text { NOT. }\end{array}$ & $\begin{array}{r}\text { NDT } \\
\text { TYPE }\end{array}$ & $\begin{array}{l}\text { AEUN } \\
\text { CTR. } \\
\text { HITS }\end{array}$ & $\begin{array}{l}\text { CTR.HIT } \\
\text { CATEGORY }\end{array}$ & $\begin{array}{l}\text { AERM } \\
\text { OYERCALL }\end{array}$ & $\begin{array}{l}\text { OYERCALL } \\
\text { CATEGORY }\end{array}$ & DISCUSSION AND COMMENTS \\
\hline 41 & $3 / 30$ & 588 & $\mathrm{~L} 61 / \times \times \times 10$ & 34.7 & 91 & & $1 / 2$ & 64 & 6 & 384 & $55-55$ & 0 & 0 & RAD & 1 & $c, 3030^{*}$ & 1 & $c, 5018^{n}$ & \\
\hline 42 & $3 / 31$ & 588 & LEl $/ X \times x=10$ & 31.9 & 88 & & $\Sigma / 2$ & 69 & 5 & 345 & $57-57$ & 0 & 0 & RAO & 0 & & 0 & & \\
\hline 43 & $4 / 02$ & 572 & $L 61 / 860$ & 32.1 & 84 & 200 & 1 & 150 & 16 & 1950 & $57-57$ & 0 & 0 & RADEUT & 0 & & 1 & $c, 4016^{\circ}$ & \\
\hline 44 & $4 / 06$ & 588 & เ61/XXX10 & 34.6 & 96 & 200 & $1-7 / 8$ & $18-16$ & 13 & 234 & $51-59$ & 1 & 0 & RAD\&\&T & 9 & $c, 2-4 ; u, 2(4)$ & 0 & & $\begin{array}{l}1 \text { VISUALY CONE IRMED TRAPPED } \\
\text { S.AG AT ENO OF R.0. TAB } \\
\text { C,1Q16" }\end{array}$ \\
\hline 45 & $4 / 06$ & 588 & $161 / x \times x 10$ & 34.6 & 96 & 200 & $1-7 / 8$ & $18-16$ & 13 & 270 & $57-59$ & 0 & 0 & RADEIT & 3 & $c, 1-3 ; u, 1$ & 2 & $\begin{array}{l}c, 104^{*} \\
u, 106^{*}\end{array}$ & GAIN WAS VARIED DURING TEST \\
\hline 46 & $4 / 06$ & 588 & เ61/xxx10 & 34.6 & 96 & 200 & $1-7 / 8$ & $18-16$ & 11 & 198 & $48-53$ & 0 & 0 & RADE्या & I & $u, 3 \Subset 8^{*}$ & 0 & & FLANGE \\
\hline 47 & $4 / 06$ & 588 & $L 61 / X \times X 10$ & 34.6 & 96 & 200 & $1-3 / 4$ & $18-16$ & 11 & 198 & $48-53$ & 0 & 0 & RADETT & 0 & & 0 & & \\
\hline 48 & $4 / 06$ & 588 & L61/XXX10 & 34.6 & 96 & 200 & $13 / 4-1$ & $20-18$ & 31 & 620 & $53-53$ & 0 & 0 & RAD\&UT & 0 & & 0 & & \\
\hline 49 & $4 / 06$ & 588 & L61/XXX10 & 34.6 & 96 & 200 & $13 / 4-1$ & $20-18$ & 19 & 320 & $53-59$ & 2 & 0 & PADEMT & 1 & u,168" & 3 & & $\begin{array}{l}\text { VISLALYY CONFIRMED SLAG IN R. } \\
\text { TAB C,1016* \& BURN THRU AT } \\
\text { u, } 4010^{*}\end{array}$ \\
\hline 50 & $4 / 07$ & 588 & LE1 $/ X X X 10$ & 34.6 & 96 & 200 & $13 / 4-1$ & $18-14$ & 10 & 180 & $52-57$ & 0 & 0 & RADEST & 0 & & 0 & & \\
\hline 51 & $4 / 07$ & 588 & L61 $/ X X X 10$ & 34.6 & 96 & 200 & $13 / 4-1$ & $20-18$ & 19 & 380 & $57-57$ & 1 & 0 & RAD\&T & $\mathrm{I}$ & $c, 2810^{n}$ & 0 & & 1 VISLALLYY CONF. ROLL U, \\
\hline 52 & $4 / 07$ & 588 & $\mathrm{~L} 61 / x \times x 10$ & 34.6 & 96 & 200 & $13 / 4-1$ & $20-18$ & 14 & 380 & $57-57$ & 0 & 0 & RAD\&:UT & 1 & $\mathrm{c}, 2 \mathrm{eg} \mathrm{B}^{\mathrm{N}}$ & 0 & & BLRIED AET 175 TRANSDUCER \\
\hline 54 & $4 / 13$ & 588 & $L 61 / 860$ & 32.6 & 84 & & $5 / 8$ & 84 & 9 & 756 & $53-57$ & 1 & 0 & RAD & 0 & & 0 & & $\begin{array}{l}1 \text { VISUALLY CONF. LOW SPDT } \\
\mathrm{c}, 50^{\circ} \text { WELED }\end{array}$ \\
\hline 55 & $4 / 14$ & 588 & $661 / 860$ & 32.6 & 84 & & $5 / 8$ & 84 & 8 & 672 & $53-55$ & 0 & 0 & RAD & 0 & & 0 & & \\
\hline 56 & $4 / 14$ & 588 & L61/860 & 32.2 & 84 & & $5 / 8$ & 84 & 7 & 588 & $53-57$ & 0 & 0 & RAD & 0 & & 5 & $\begin{array}{l}c, 2 ; c, 3 ; \\
2 c, 4 ;\end{array}$ & $\begin{array}{l}\text { INDICAT IONS BECAN IN FOOT } \\
\text { PASS }\end{array}$ \\
\hline 57 & $4 / 22$ & 588 & $\mathrm{~L} 61 / x \times x 10$ & 32.6 & 86 & & $5 / 8$ & 66 & 7 & 462 & $55-55$ & 0 & 0 & RAD\&dT & 1 & $c_{0} 1930^{*}$ & 0 & $i 0,5$ & \\
\hline 58 & $4 / 23$ & 588 & $L 61 / x \times \times 10$ & 32.6 & 84 & & $5 / 8$ & 65 & 7 & 455 & $55-57$ & 0 & 0 & PADIUT & 0 & & 0 & & \\
\hline 59 & $4 / 24$ & 588 & $161 / x \times \times 10$ & 32.8 & 86 & & $5 / 8$ & 66 & 8 & 528 & $55-57$ & 1 & 0 & RADथT & 0 & & 0 & & $\begin{array}{l}2 \text { VISLALLYY CONF. LOW SPOT } \\
\text { ROOT PASS U2,E34" }\end{array}$ \\
\hline 60 & $4 / 29$ & 588 & $L 61 / X \times \times 10$ & 32.6 & 86 & & $5 / 8$ & 66 & 7 & 462 & $55-59$ & 0 & 0 & RAD\&UT & 1 & u,1@30" & 0 & & \\
\hline 61 & $4 / 30$ & 588 & $L 61 / \times \times \times 10$ & 32.6 & 86 & & $5 / 8$ & 56 & 5 & 396 & $53-55$ & 0 & 0 & RADQUT & 0 & & 0 & & \\
\hline 62 & $4 / 30$ & 588 & $\mathrm{~L} 61 / x \times x \times 10$ & 32.4 & 88 & & $5 / 8$ & 67 & 7 & 469 & $55-57$ & 0 & 0 & RAD\&UT & 0 & & 0 & & \\
\hline 63 & $5 / 07$ & 572 & L.61/860 & 35.0 & 95 & & $11 / 16$ & 65 & 5 & 325 & $53-53$ & 0 & 0 & RAD\&UT & 1 & $u, 2928^{*}$ & 0 & & \\
\hline
\end{tabular}


TABLE 1. AEM FABRICAT ION SHOP TEST DATA (CONTI MUED)

\begin{tabular}{|c|c|c|c|c|c|c|c|c|c|c|c|c|c|c|c|c|c|c|c|}
\hline $\begin{array}{l}\text { WELD } \\
\text { No. }\end{array}$ & $\begin{array}{l}\text { TEST } \\
\text { DATE }\end{array}$ & $\begin{array}{l}\text { WELD } \\
\text { MATL. }\end{array}$ & $\begin{array}{l}\text { HIREI } \\
\text { FLUXX }\end{array}$ & $\begin{array}{l}\text { WEL1D } \\
\text { VOLT }\end{array}$ & $\begin{array}{l}\text { WELL } \\
\text { SPD. } \\
\text { (IPM) }\end{array}$ & $\begin{array}{l}\text { PRE- } \\
\text { HEAT } \\
\left({ }^{\circ} \mathrm{F}\right)\end{array}$ & $\begin{array}{l}\text { MATL. } \\
\text { THK. } \\
\text { (IK.) }\end{array}$ & $\begin{array}{l}\text { WE.D } \\
\text { LG. } \\
\text { (IN.) }\end{array}$ & $\begin{array}{l}\text { HELLD } \\
\text { PASSES }\end{array}$ & $\begin{array}{l}\text { TOT.LG. } \\
\text { INSP. } \\
\text { (IN.) }\end{array}$ & $\begin{array}{l}\text { AENM } \\
\text { GAIN } \\
\text { (dB) }\end{array}$ & $\begin{array}{l}\text { VALID } \\
\text { AEAM } \\
\text { INEIC. }\end{array}$ & $\begin{array}{l}\text { CONV. } \\
\text { NoT. }\end{array}$ & $\begin{array}{l}\text { NDT } \\
\text { TYPE }\end{array}$ & $\begin{array}{l}\text { AEMM } \\
\text { CTR. } \\
\text { HITS }\end{array}$ & $\begin{array}{l}\text { CTR. HIT } \\
\text { CAYEGORY }\end{array}$ & $\begin{array}{l}\text { AEAM } \\
\text { OVERCALL }\end{array}$ & $\begin{array}{l}\text { OVERCALL } \\
\text { CATEGORY }\end{array}$ & DISCUSSION AND COMMENTS \\
\hline 64 & $5 / 07$ & 572 & L61/860 & 35.0 & 95 & & $11 / 16$ & 64 & 5 & 320 & $53-53$ & 2 & 0 & RAD\&UT & 1 & $c, 1930^{\circ \prime}$ & 0 & & $\begin{array}{l}\text { CRATER CRACK VI SUALLY DETECTED } \\
\text { C,1 \& } \mathrm{C}, 2 \text { E10", WELDED } \\
\text { AND REPA IRED }\end{array}$ \\
\hline 65 & $5 / 07$ & 572 & $L 61 / 860$ & 35.0 & 95 & & $11 / 16$ & 65 & 6 & 390 & $53-53$ & 6 & 0 & RAD\&UT & 0 & & 0 & & $\begin{array}{l}\text { VISLALY CONF. SLAG INCLUSION } \\
12^{*} \text { LONG. GROLND OUT AND } \\
\text { REAIRED }\end{array}$ \\
\hline 66 & $5 / 07$ & 572 & L61/860 & 35.0 & 95 & & $11 / 16$ & 65 & 5 & 325 & $53-53$ & 0 & 0 & RAD\&JT & 0 & & 0 & & \\
\hline 67 & $5 / 13$ & 572 & L61/860 & 34.0 & 72 & & $3 / 4$ & 72 & 6 & 432 & $55-57$ & 0 & 0 & RAD\&UT & 1 & $u, 2034^{n}$ & 0 & & \\
\hline 68 & $5 / 14$ & 572 & $1.61 / 860$ & 34.0 & 85 & & $3 / 4$ & 73 & 7 & 438 & $55-57$ & 0 & 0 & RAD\&IT & 2 & $\begin{array}{l}\text { u,3032" } \\
\text { u, } 3034^{n}\end{array}$ & 2 & $\begin{array}{l}\mathrm{C,164^{n }} \\
\mathrm{u}, 2620^{n}\end{array}$ & \\
\hline 69 & $5 / 14$ & 572 & $\llcorner 61 / 860$ & 34.0 & 85 & & $3 / 4$ & 73 & 7 & 511 & $55-57$ & 0 & 0 & RAD\& & 2 & $\begin{array}{l}u, i[34 " \\
c, 2 \notin 32^{*}\end{array}$ & 0 & & \\
\hline 70 & $5 / 19$ & $5 / 2$ & $\llcorner 61 / 860$ & 34.0 & 86 & & $3 / 4$ & 72 & 6 & 432 & $55-57$ & 0 & 0 & RA@ะ्यT & 0 & & 0 & & \\
\hline 71 & $5 / 19$ & 572 & $L 61 / 860$ & 34.0 & 85 & & $3 / 4$ & 73 & 6 & 438 & $57-57$ & 1 & 0 & RADEUT & 0 & & 0 & & $\begin{array}{l}\text { VISUALIY CONF. SLAG U,1036" } \\
\text { GROUND OUT }\end{array}$ \\
\hline 72 & $5 / 19$ & 572 & LG1/860 & 34.0 & 85 & & $3 / 4$ & 73 & 6 & 438 & $55-57$ & 0 & 0 & RADOUT & 0 & & 0 & & \\
\hline 73 & $5 / 22$ & 572 & $\mathrm{~L} 6 \mathrm{~L} / 860$ & 32.6 & 86 & & $5 / 8$ & 92 & 6 & 552 & $55-57$ & 0 & 0 & RADSUT & 0 & & 0 & & \\
\hline 74 & $5 / 22$ & 572 & $261 / 860$ & 34.0 & 86 & & $5 / 8$ & 93 & 5 & 465 & $57-57$ & 0 & 0 & RADEJT & 2 & $u, 1 \notin 44=u, 2 \notin 42$ & 0 & & \\
\hline 75 & $5 / 22$ & 572 & $L 61 / 860$ & 32.2 & 86 & & $5 / 8$ & 93 & 5 & 465 & $55-55$ & 0 & 0 & RADE: TT & 0 & & 0 & & \\
\hline 76 & $6 / 09$ & $5 / 2$ & $L G / 860$ & 34.0 & 85 & & $5 / 8$ & 64 & 5 & 320 & $57-55$ & 0 & 0 & RAD & 2 & $\begin{array}{l}u, 1 @ 32^{n} \\
u, 1028^{n}\end{array}$ & 0 & & \\
\hline 77 & $5 / 09$ & 572 & L61/860 & 34.2 & 86 & & $5 / 8$ & 63 & 5 & 315 & $59-55$ & 0 & 0 & RAD & 0 & & 0 & & \\
\hline 78 & $6 / 11$ & 572 & $L 61 / 860$ & 34.0 & 85 & & $5 / 8$ & 63 & 5 & 315 & $57-57$ & 0 & 0 & RAD & 2 & $\begin{array}{l}c, 2030^{*} \\
c, 1 @ 30^{=}\end{array}$ & 0 & & \\
\hline 79 & $6 / 11$ & 572 & $161 / 860$ & 34.0 & 85 & & $5 / 8$ & 62 & 6 & 372 & $57-55$ & 0 & 0 & RAD & 0 & & 0 & & \\
\hline 80 & $6 / 12$ & 572 & $\mathrm{~L} 61 / 860$ & 34.0 & 86 & & $5 / 8$ & 63 & 6 & 378 & $57-55$ & 0 & 0 & RAD & 1 & $u, 4028^{n}$ & 0 & & FLANGE \\
\hline 81 & $7 / 10$ & 588 & L61/860 & 34.0 & 129 & 200 & $23 / 8-1$ & 18 & 11 & 198 & $51-61$ & 0 & 0 & RAD\&UT & 0 & & 0 & & \\
\hline 82 & $7 / 10$ & 588 & L61/860 & 34.0 & 129 & 200 & $23 / 8-1$ & 18 & 12 & 216 & $61-63$ & 0 & 0 & RAD\&UT & 1 & $u, 3010^{\circ}$ & 1 & $4,186^{n}$ & FLANGE \\
\hline 83 & $7 / 13$ & 588 & L61/850 & 34.0 & 128 & 200 & $15 / 8-1$ & 18 & 11 & 198 & $59-61$ & 0 & 0 & RAD\&UT & 1 & $u, 2 \notin 8^{n}$ & 0 & & $\begin{array}{l}\text { RAN OUT OF FLUX DURIMG PASS, } \\
\text { NO REPAIR }\end{array}$ \\
\hline 84 & $7 / 14$ & 588 & $161 / 860$ & 34.0 & 128 & 200 & $5 / 8-1$ & 18 & 14 & 198 & $59-61$ & 0 & 0 & RAD\&ST & 0 & & 0 & & \\
\hline
\end{tabular}


TABLE 1. AELM FARICATION SHOP TEST DATA (CONTINNE)

\begin{tabular}{|c|c|c|c|c|c|c|c|c|c|c|c|c|c|c|c|c|c|c|c|}
\hline $\begin{array}{l}\text { WELD } \\
\text { NO. }\end{array}$ & $\begin{array}{l}\text { TEST } \\
\text { DATE }\end{array}$ & $\begin{array}{l}\text { WELD } \\
\text { NATL. }\end{array}$ & $\begin{array}{l}\text { WTRE/ } \\
\text { FWXX }\end{array}$ & $\begin{array}{l}\text { WELLD } \\
\text { YOLT }\end{array}$ & $\begin{array}{l}\text { WELD } \\
\text { SPD. } \\
\text { (IPM) }\end{array}$ & $\begin{array}{l}\text { RRE- } \\
\text { HEAT } \\
\left({ }^{\circ} \mathrm{F}\right)\end{array}$ & $\begin{array}{l}\text { MARL } \\
\text { THK. } \\
\text { (IN.) }\end{array}$ & $\begin{array}{l}\text { WE. } \\
\text { LG. } \\
\text { (IN.) }\end{array}$ & $\begin{array}{l}\text { WELD } \\
\text { PASSES }\end{array}$ & $\begin{array}{l}\text { TOT.LG. } \\
\text { INSP. } \\
\text { (IN.) }\end{array}$ & $\begin{array}{l}\text { AENM } \\
\text { GAIN } \\
\text { (dB) }\end{array}$ & $\begin{array}{l}\text { VALIO } \\
\text { AEMM } \\
\text { INDIC. }\end{array}$ & $\begin{array}{l}\text { CONV. } \\
\text { NDT. }\end{array}$ & $\begin{array}{l}\text { NDT } \\
\text { TYPE }\end{array}$ & $\begin{array}{l}\text { AEMM } \\
\text { CTR. } \\
\text { HITS }\end{array}$ & $\begin{array}{l}\text { CTR.HIT } \\
\text { CATEGORY }\end{array}$ & $\begin{array}{l}\text { AEMM } \\
\text { OVERCALL }\end{array}$ & $\begin{array}{l}\text { OVERCALL } \\
\text { CATEGORY }\end{array}$ & DISCUSSION AND COMMENTS \\
\hline 85 & $7 / 17$ & 588 & L61/860 & 33.1 & 83 & & $9 / 16$ & 62 & 5 & 310 & $55-57$ & 0 & 0 & RAQ\&UT & 1 & $c, 1830^{n}$ & 3 & $\begin{array}{l}c, 1620^{*} \\
u, 5 \oplus 16^{*} \\
c, 2224^{*}\end{array}$ & SLAG IN R.P., u,5116*; CHIPPED \\
\hline 86 & $7 / 20$ & 588 & $161 / 860$ & 33.0 & 83 & & $9 / 16$ & 63 & 5 & 315 & $53-55$ & 0 & 0 & RAD束T & 0 & & 0 & & \\
\hline 87 & $7 / 21$ & 588 & L61/860 & 33.0 & 83 & & $9 / 16$ & 63 & 5 & 315 & $53-55$ & 0 & 0 & RAD\&NT & 0 & & 0 & & \\
\hline 88 & $7 / 24$ & 588 & L61/860 & 34.0 & 128 & 200 & 1 & 16 & 11 & 176 & $59-61$ & 0 & 0 & RAD & 0 & & 1 & $u, 4910^{*}$ & \\
\hline 89 & $7 / 27$ & 588 & L61/860 & 34.0 & 128 & 200 & 1 & 16 & 9 & 154 & $59-63$ & 0 & 0 & RAD & 0 & & 1 & $c, 18^{n}$ & \\
\hline 90 & $7 / 29$ & 588 & $561 / x \times x-10$ & 32.0 & 86 & & $1 / 2$ & 62 & 5 & 310 & $55-59$ & 0 & 0 & RAD & 1 & $c, 1 @ 32^{n}$ & 1 & c,1826" & \\
\hline 91 & $7 / 30$ & 588 & L61/XXX-I0 & 32.0 & 86 & & $1 / 2$ & 63 & 5 & 315 & $53-55$ & 1 & 0 & RAD & 0 & & 0 & & $\begin{array}{l}\text { VIS. CONF. SLAG U,2G20" GROLND } \\
\text { OUT }\end{array}$ \\
\hline 92 & $7 / 30$ & 588 & $L 61 / X X X=10$ & 32.0 & 86 & & $1 / 2$ & 62 & 5 & 310 & $55-57$ & 1 & 1 & RAD & 0 & & 0 & & $\begin{array}{l}\text { VIS. CONF. NOT SLAG } c, 6 \text { NAn }^{\prime} \text { BAD } \\
\text { REPA IR. CONFIRMED BY RADIOGRAPHY }\end{array}$ \\
\hline 93 & $8 / 03$ & 588 & $L 61 / X X X-10$ & 32.0 & 86.5 & & $1 / 2$ & 63 & 5 & 315 & $57-57$ & 0 & 0 & RAD & 0 & & 0 & & \\
\hline 94 & $8 / 03$ & 588 & $561 / X X X-10$ & 32.0 & 86 & & $1 / 2$ & 63 & 5 & 315 & $57-59$ & 0 & 0 & RAD & 0 & & 2 & u. 6е28" & \\
\hline 95 & $8 / 04$ & 588 & L.61/ $/ x \times x-10$ & 32.0 & 86 & & $1 / 2$ & 62 & 6 & 372 & $53-55$ & 0 & 0 & RAD & 0 & & 0 & & \\
\hline 96 & $8 / 04$ & 588 & L61/xxx-10 & 32.0 & 86 & & $1 / 2$ & 62 & 5 & 310 & $55-57$ & 0 & 0 & RAD & 0 & & 0 & & \\
\hline 97 & $8 / 06$ & 538 & $\mathrm{~L} 61 / 860$ & 35.0 & 129 & 200 & $21 / 4-1$ & 24 & 13 & 312 & $63-65$ & 0 & 0 & RAD & 1 & L, 3012" & 1 & $c, 2814^{n}$ & \\
\hline 98 & $8 / 07$ & 588 & L61/860 & 35.0 & 129 & 200 & $21 / 4-1$ & 23 & 14 & 322 & $59-63$ & 0 & 0 & RAD & 1 & $c, 408^{\prime \prime}$ & 1 & c,2@12" & \\
\hline 99 & $8 / 20$ & 588 & L61/860 & 34.0 & 128 & 300 & $21 / 8-1$ & 22 & 13 & 256 & $59-61$ & 0 & 0 & RAD & 0 & & 0 & & \\
\hline 100 & $8 / 30$ & 588 & $\mathrm{~L} 61 / 860$ & 34.4 & 128 & 300 & $21 / 8-1$ & 20 & 13 & 260 & $63-65$ & 2 & 0 & RAD & I & $u, 3610^{n}$ & 1 & & $\begin{array}{l}c, 2 \& c, 4 C B \text { " PINROLE PORSITY } \\
\text { REPAIRED u, 3910" LOSS OF FLUX }\end{array}$ \\
\hline 101 & $8 / 11$ & 588 & L61/860 & 35.0 & 128 & 300 & $2-1$ & 19 & 13 & 247 & $63-67$ & 0 & 0 & RAD & I & $u, 4 \oplus 8^{*}$ & 0 & & \\
\hline 102 & $8 / 13$ & 588 & $261 / 860$ & 35.0 & 129 & 250 & $25 / 8-1 \quad 1 / 2$ & 20 & 16 & 320 & $61-66$ & 0 & 0 & RAD & 4 & $\begin{array}{l}u, 4-u, 5 ; \\
c, 1-c, 2\end{array}$ & 3 & $\begin{array}{l}c, 1914^{n} \\
c, 5912^{n} \\
u, 2012^{*}\end{array}$ & \\
\hline 103 & $8 / 14$ & 588 & L61/860 & 35.0 & 129 & 250 & $25 / 8-1 \quad 1 / 2$ & 20 & 16 & 340 & $61-63$ & 0 & 0 & RAD & 0 & & 2 & $\begin{array}{l}c, 106 " \\
4,3012^{n}\end{array}$ & u,3Q12" OCCURRED, RAN OUT OF UIPE \\
\hline 104 & $8 / 17$ & 588 & L61/860 & 35.0 & 129 & 250 & $25 / 8-1 \quad 1 / 2$ & 20 & 17 & 380 & $61-59$ & 1 & 0 & RAD & 0 & & & & $\begin{array}{l}\text { U,2巨10* TRAPPED SLAG CHIPPED AND } \\
\text { GROJND OUT. VISUAШY CONFIRMED }\end{array}$ \\
\hline 105 & $8 / 17$ & 588 & L61/860 & 35.0 & 129 & 250 & $25 / 8-1 \quad 1 / 2$ & 20 & 16 & 256 & $61-63$ & 0 & 0 & RAD & 1 & C,188"; & 1 & $c .3012^{*}$ & \\
\hline
\end{tabular}


TABLE 1. AELM FABRICATION SHOP TEST DATA (CONTINUD)

\begin{tabular}{|c|c|c|c|c|c|c|c|c|c|c|c|c|c|c|c|c|c|c|c|}
\hline WEL & $\begin{array}{l}\text { TEST } \\
\text { DATE }\end{array}$ & $\begin{array}{l}\text { WELD } \\
\text { MATL. }\end{array}$ & $\begin{array}{l}\text { HIREI } \\
\text { FLUX }\end{array}$ & $\begin{array}{l}\text { WELD } \\
\text { vOLT }\end{array}$ & $\begin{array}{l}\text { WELLD } \\
\text { SPD. } \\
\text { (IPM) }\end{array}$ & $\begin{array}{l}\text { PRE- } \\
\text { HEAT } \\
\left({ }^{\circ} \mathrm{F}\right)\end{array}$ & $\begin{array}{l}\text { MATL } \\
\text { THK. } \\
\text { (IN.) }\end{array}$ & $\begin{array}{l}\text { WEBD } \\
\text { LG. } \\
\text { (IN.) }\end{array}$ & $\begin{array}{l}\text { WELD } \\
\text { PASSES }\end{array}$ & $\begin{array}{l}\text { TOT.LG. } \\
\text { INSP. } \\
\text { (IN.) }\end{array}$ & $\begin{array}{l}\text { AEAM } \\
\text { GAIN } \\
\text { (dB) }\end{array}$ & $\begin{array}{l}\text { VALID } \\
\text { AEMM } \\
\text { INDIC. }\end{array}$ & $\begin{array}{l}\text { CONV. } \\
\text { ner. }\end{array}$ & $\begin{array}{l}\text { NDT } \\
\text { TYPEE }\end{array}$ & $\begin{array}{l}\text { AENM } \\
\text { CTR. } \\
\text { HITS }\end{array}$ & $\begin{array}{r}\text { CTR.HIT } \\
\text { CATEGORY }\end{array}$ & $\begin{array}{l}\text { AEMM } \\
\text { OVERCALL }\end{array}$ & $\begin{array}{l}\text { OLERCALL } \\
\text { CATEGORY }\end{array}$ & DISCUSSION AND COMMENTS \\
\hline 106 & $8 / 18$ & 588 & L61/860 & 35.0 & 129 & 250 & $25 / 8-11 / 2$ & 20 & 16 & 256 & $59-61$ & 0 & 0 & RAD & 3 & $\begin{array}{l}u, 3,4010^{\circ} ; \\
u, 5010^{\circ}\end{array}$ & 1 & $u_{0} 6014^{n}$ & \\
\hline 107 & $8 / 21$ & 572 & L61 /850 & 32.7 & 87 & & $3 / 4$ & 62 & 7 & 434 & $55-55$ & 0 & 0 & RAD & 0 & & 0 & & \\
\hline 108 & $8 / 21$ & 572 & L61/860 & 32.5 & 86.5 & & $3 / 4$ & 62 & 8 & 496 & $57-57$ & 0 & 0 & RAD & 1 & $u, 1028^{m}$ & 1 & $u, 2014^{n}$ & \\
\hline 109 & $8 / 25$ & A36 & L61/860 & 31.0 & 86 & & $1 / 2$ & 74 & 5 & 370 & $55-55$ & 0 & 0 & RAD & 0 & & 0 & & \\
\hline 110 & $8 / 26$ & $A 36$ & $\llcorner 61 / 860$ & 32.0 & 93. & & $1 / 2$ & 74 & 5 & 370 & $53-55$ & 0 & 0 & RAD & 2. & $\begin{array}{l}u, 6834^{*} \\
c, 3822^{n}\end{array}$ & 1 & $4,1026 "$ & DUE TO CHIPPING \\
\hline 111 & $9 / 02$ & 588 & $561 / x x x x-10$ & 32.0 & 87.5 & & $1 / 2$ & 54 & 5 & 270 & $53-53$ & 0 & 0 & RAD & 1 & $u, 5 \otimes 22^{n}$ & 0 & & \\
\hline 112 & $9 / 02$ & 588 & $161 / x \times x-10$ & 32.0 & 87 & & $1 / 2$ & 54 & 5 & 20 & $53-57$ & 0 & 0 & RAD & 0 & & 0 & & \\
\hline 113 & $9 / 03$ & 588 & $561 / x \times x=10$ & 32.0 & 87 & & $1 / 2$ & 54 & 5 & 270 & $55-55$ & 0 & 0 & RAD & 0 & & 0 & & \\
\hline 114 & $9 / 08$ & 588 & L61/xxx-10 & 32.0 & 87.5 & & $1 / 2$ & 54 & 6 & 324 & $55-53$ & 0 & 0 & RAD & 0 & & 0 & & \\
\hline 115 & $9 / 08$ & 588 & $161 / x x x-10$ & 32.5 & 88.1 & & $1 / 2$ & 54 & 5 & 270 & $57-59$ & 0 & 0 & RAD & 1 & $c, 3024^{N}$ & 0 & & \\
\hline 116 & $9 / 08$ & 588 & L61/xxx-10 & 32.5 & 88 & & $1 / 2$ & 54 & 5 & 270 & $55-57$ & 0 & 0 & PAD & 0 & & 0 & & \\
\hline 117 & $9 / 10$ & 572 & $\mathrm{~L} 61 / 860$ & 31.0 & 93 & 250 & $21 / 2$ & 22 & 24 & 528 & $53-53$ & 0 & 0 & RAD & 0 & & 1 & $C, 1 B 6=$ & PINHGLE PORSITY POSSTBLE \\
\hline 118 & $9 / 11$ & 572 & $\mathrm{~L} 61 / 860$ & 31.5 & 92 & 250 & $21 / 2$ & 22 & 23 & 506 & $53-55$ & 0 & 0 & RAD & 0 & & 0 & & \\
\hline 119 & $9 / 14$ & A36 & $161 / 860$ & 33.8 & 92 & & $3 / 4$ & 108 & 6 & 648 & $53-55$ & 0 & 0 & RAD & I & $c, 21652^{n}$ & 2 & $\begin{array}{l}u, 2840^{\circ} ; \\
c, 3038^{\circ}\end{array}$ & $\begin{array}{l}\text { RAN OUT OF WIRE DURING PASS; } \\
\text { DUE TO CHIPPING }\end{array}$ \\
\hline 120 & $9 / 14$ & A36 & $\mathrm{L} 61 / 860$ & 33.8 & 92 & & $3 / 4$ & 108 & 7 & 756 & $55-53$ & 0 & 0 & RAD & 1 & $6,3054^{\prime \prime}$ & 1 & c. $1858^{\circ}$ & OUE TO CHIPPING \\
\hline 121 & $9 / 15$ & A36 & L61/860 & 33.6 & 91 & & $3 / 4$ & 108 & 7 & 756 & $57-53$ & 0 & 0 & RAD & 0 & & 1 & $u, 3016^{u}$ & \\
\hline 122 & $9 / 17$ & 572 & L61/860 & 31.8 & 84 & & $7 / 16$ & 63 & 6 & 378 & $55-57$ & 0 & 0 & RAD\&AT & 0 & & 0 & & \\
\hline 123 & $9 / 17$ & 572 & L61/860 & 31.8 & 84 & & $7 / 16$ & 63 & 5 & 315 & $57-55$ & 0 & 0 & RAO\&UT & 0 & & 0 & & \\
\hline 124 & $9 / 18$ & 572 & LII $/ 860$ & 31.9 & 86 & & $7 / 16$ & 64 & 5 & 320 & $55-55$ & 0 & 0 & RADEJT & 0 & & 0 & & \\
\hline 125 & $9 / 21$ & 572 & LELI/860 & 31.5 & 85 & & $7 / 16$ & 63 & 5 & 315 & $57-57$ & 0 & 0 & RAD\&UT & 0 & & 0 & & \\
\hline 126 & $9 / 21$ & 572 & L6! $/ 850$ & 31.9 & 83 & & $7 / 16$ & 63 & 5 & 315 & $55-55$ & 0 & 0 & RAD\&UT & 0 & & 1 & c,3@22" & \\
\hline 127 & $9 / 22$ & 572 & $\mathrm{~L} 6 \mathrm{~L} / 860$ & 31.8 & 85 & & $7 / 16$ & 63 & 6 & 378 & $55-57$ & 0 & 0 & RADEUT & 0 & & 1 & u,2@26" & RAN OUT OF FLUX DUR ING PASS \\
\hline 128 & $9 / 22$ & 572 & $\pm 61 / 860$ & 31.9 & 83 & & $7 / 16$ & 63 & 5 & 315 & $53-55$ & 0 & 0 & RAOEAT & 0 & & 0 & & \\
\hline 129 & $9 / 23$ & 572 & $L, 61 / 860$ & 31.9 & 83 & & $7 / 16$ & 63 & 4 & 252 & $57-59$ & 0 & 0 & RAD\&UT & 0 & & 1 & $c, 3634^{\prime \prime}$ & \\
\hline
\end{tabular}


TABLE 1. AELM FABRICATION SHOP TEST DATA (CONTINUD)

\begin{tabular}{|c|c|c|c|c|c|c|c|c|c|c|c|c|c|c|c|c|c|c|c|}
\hline $\begin{array}{l}\text { WEL } \\
\text { NO. }\end{array}$ & $\begin{array}{l}\text { TEST } \\
\text { DATE }\end{array}$ & $\begin{array}{l}\text { WELE } \\
\text { MATL. }\end{array}$ & $\begin{array}{l}\text { HIRE/ } \\
\text { FWXX }\end{array}$ & $\begin{array}{l}\text { WEED } \\
\text { VOLT }\end{array}$ & $\begin{array}{l}\text { WELD } \\
\text { SPD. } \\
\text { (IPM) }\end{array}$ & $\begin{array}{l}\text { PRE- } \\
\text { HEAT } \\
\left({ }^{\circ} \mathrm{F}\right)\end{array}$ & $\begin{array}{l}\text { MATL } \\
\text { THK. } \\
\text { (IN.) }\end{array}$ & $\begin{array}{l}\text { WE. } \\
\text { LG. } \\
\text { (IN.) }\end{array}$ & $\begin{array}{l}\text { WELD } \\
\text { PASSES }\end{array}$ & $\begin{array}{c}\text { TOT.LG. } \\
\text { INSP. } \\
\text { (IN.) }\end{array}$ & $\begin{array}{l}\text { AEHM } \\
\text { GAIN } \\
\text { (dB) }\end{array}$ & $\begin{array}{c}\text { YALID } \\
\text { AEMM } \\
\text { INDIC. }\end{array}$ & $\begin{array}{l}\text { CONY. } \\
\text { NDT. }\end{array}$ & $\begin{array}{l}\text { NOT } \\
\text { TYPE }\end{array}$ & $\begin{array}{l}\text { AEWM } \\
\text { CTR. } \\
\text { HITS }\end{array}$ & $\begin{array}{l}\text { CTR.HIT } \\
\text { CATEGORY }\end{array}$ & $\begin{array}{c}\text { AEMM } \\
\text { OVERCALL }\end{array}$ & $\begin{array}{l}\text { OVERCAIL } \\
\text { CATEGORY }\end{array}$ & DISCUSSION AND COMMENTS \\
\hline 130 & $9 / 23$ & 572. & L61/860 & 31.9 & 83 & & $7 / 16$ & 63 & 4 & 252 & $57-55$ & 0 & 0 & RADEUT & 1 & $u_{0} 4028^{\circ}$ & 1 & $u, 5638^{n}$ & \\
\hline 131 & $9 / 25$ & $A 36$ & $161 / 860$ & 33.8 & 35 & 250 & $11 / 8$ & 18 & 12 & 216 & $59-59$ & 0 & 0 & RAO & 1 & $c, 2066^{*}$ & 0 & & \\
\hline 132 & $9 / 28$ & A36 & L61/860 & 33.8 & 85 & 250 & $11 / 8$ & 18 & 10 & 180 & $55-55$ & 0 & 0 & RAD & 1 & $u, 1 \notin \theta^{\prime \prime}$ & 0 & & \\
\hline 133 & $9 / 29$ & $A 36$ & $161 / 860$ & 34.0 & 90 & 250 & $1 \mathrm{l} / \mathrm{8}$ & 18 & 11 & 198 & $53-53$ & 5 & 0 & RAD & 1 & $y, 2186^{\prime \prime}$ & 0 & & DEFECT CONFIRMED BY RADIOGRAPHY \\
\hline 134 & $9 / 29$ & A36 & $\lfloor 61 / 860$ & 33.8 & 85 & 250 & $1 \mathrm{I} / 8$ & 18 & 10 & 180 & $53-53$ & 0 & 0 & RAO & 1 & $c .106^{\circ}$ & 0 & & \\
\hline 135 & $10 / 01$ & $A 36$ & $161 / 860$ & 32.0 & 85 & & $1 / 2$ & 75 & 5 & 375 & $53-53$ & 0 & 1 & RAD & 0 & & 0 & & \\
\hline 136 & $10 / 02$ & A36 & L61/860 & 31.8 & 83 & & $7 / 16$ & 66 & 4 & 264 & $53-53$ & 0 & 0 & RAD & 0 & & 0 & & \\
\hline$\$ 37$ & $10 / 02$ & A36 & L61 / 860 & 31.9 & 83 & 250 & $1 / 2-5 / 8$ & 16 & 12 & 192 & $53-55$ & 0 & 0 & RAD & 0 & & 0 & & NDT NOT REQUIRED \\
\hline 138 & $10 / 02$ & $A 36$ & $161 / 860$ & 34.6 & 85 & & 1 & 65 & 4 & 260 & $55-57$ & 0 & 0 & RAD & 0 & & 2 & $\begin{array}{l}\text { u,1826"; } \\
\text { u,186" }\end{array}$ & \\
\hline 139 & $10 / 06$ & 598 & LQR/860 & 32.7 & 87 & 250 & 1 & 16 & 13 & 208 & $55-57$ & 0 & 0 & RAD & 1 & U,iEs" & 0 & & NOT HOT REQUIRED \\
\hline 140 & $10 / 07$ & 588 & L61/860 & 32.5 & 85 & 250 & $1 / 2-5 / 8$ & 16 & 12 & 192 & $53-55$ & 0 & 0 & RAD & 0 & & 0 & & NOT NOT REQUIRED \\
\hline 141 & $10 / 07$ & 588 & $L 61 / 860$ & 32.0 & 85 & 250 & $1 / 2-5 / 8$ & 16 & 12 & 192 & $53-55$ & 0 & 0 & RAD & 0 & & 0 & & NDT NOT REQUIRED \\
\hline 142 & $10 / 12$ & 588 & $\mathrm{~L} 6 \mathrm{~L} / \mathrm{XXX} \mathrm{x}-\mathrm{10} 0$ & 34.5 & 94 & & $1 / 2-5 / 8$ & 61 & 4 & 244 & $53-55$ & 1 & 0 & RAD & 0 & & 0 & $c, 6018^{4}$ & $\begin{array}{l}\text { VISUALYY CONF YRMED LQN SPOT } \\
\text { GROUND OUT AND RERAIRED }\end{array}$ \\
\hline 143 & $10 / 13$ & 588 & L61/XXX-10 & 34.0 & 93 & & $1 / 2-5 / 8$ & a & 5 & 305 & $53-55$ & 0 & 0 & RAD & 0 & & 0 & & \\
\hline 144 & $10 / 13$ & 589 & $6.61 / x \times x-10$ & 34.5 & 94 & & $i / 2$ & 61 & 4 & 244 & $55-57$ & 0 & 0 & RAD & 2 & $\begin{array}{l}c, 4028^{\prime \prime} \\
c, 1028^{\prime \prime}\end{array}$ & 3 & $\begin{array}{l}c, 4012^{\circ} ; \\
\text { u, } 6012^{*}\end{array}$ & \\
\hline 145 & $10 / 14$ & 588 & $261 / x \times x-10$ & 34.5 & 94 & & $1 / 2$ & 61 & 4 & 244 & $53-55$ & 0 & 0 & RAD & 0 & & 0 & , & \\
\hline 146 & $10 / 14$ & 588 & $L 61 / X X X-10$ & 34.5 & 93 & & $1 / 2$ & 75 & 5 & 375 & $56-57$ & 0 & 0 & RAD & 0 & & 0 & & \\
\hline 147 & $10 / 20$ & 588 & L6I $/ X X X=10$ & 34.5 & 93 & & $1 / 2$ & 75 & 5 & 375 & $53-55$ & 0 & 0 & RAD & 0 & & 1 & u,1022" & \\
\hline 148 & $10 / 20$ & 588 & $161 / x x x-10$ & 34.5 & 93 & & $1 / 2$ & 75 & 5 & 375 & $53-55$ & 0 & 0 & RAD & 0 & & 0 & & \\
\hline 149 & $10 / 22$ & 588 & $161 / x \times x=10$ & 34.5 & 93 & & $1 / 2$ & 75 & 4 & 300 & $53-55$ & 0 & 0 & RAD & 0 & & 1 & $c, 4842^{\prime \prime}$ & \\
\hline 150 & $10 / 23$ & 588 & $L 61 / X X X-10$ & 34.5 & 93 & & $1 / 2$ & 75 & 4 & 300 & $53-55$ & 0 & 0 & RAD & 0 & & 0 & & \\
\hline 151 & $10 / 26$ & 588 & $561 / x \times x-10$ & 32.7 & 93 & & $1 / 2$ & 75 & 5 & 375. & $53-55$ & 0 & 0 & RAD & 0 & & 0 & & ERROR ON PPDJECT NIMBER - NOT TESTED \\
\hline 152 & $10 / 26$ & 588 & $\mathrm{~L} 61 / \mathrm{XXXX}-10$ & 32.5 & 94 & & $1 / 2$ & 75 & 5 & 375 & $53-55$ & 0 & 0 & RAD & 0 & & 0 & & ERROR ON PROJECT MEMBER - NOT TESTED \\
\hline 153 & $10 / 28$ & 588 & $161 / x x x-10$ & 35.0 & 94 & & $1 / 2$ & 73 & 6 & 438 & $53-55$ & 0 & 0 & RAD & 0 & & 0 & & \\
\hline
\end{tabular}


TABLE 2. SUMMARY OF AEWM TESTING (WEB WELDS)

\begin{tabular}{|c|c|}
\hline Weld Length Monitored & 673.5 feet \\
\hline Total Number of Welds Monitored & 114 \\
\hline Average Weld Length Monitored & 70.9 inches \\
\hline Total Number of Weld Passes Monitored & 654 \\
\hline Total Length of Weld Passes Monitored & $3,860.9$ feet \\
\hline Total Number of AEWM Indications & 191 \\
\hline $\begin{array}{l}\text { Total Number of Valid Indications } \\
\text { (Percent of Total) }\end{array}$ & $\begin{array}{l}25 \\
(13.1)\end{array}$ \\
\hline $\begin{array}{l}\text { Total Number of Center Hit Indications } \\
\text { (Percent of Total) }\end{array}$ & $\begin{array}{l}90 \\
(47.1)\end{array}$ \\
\hline $\begin{array}{l}\text { Total Number of Unconfirmed Indications } \\
\text { (Percent of Tota1) }\end{array}$ & $\begin{array}{l}76 \\
(39.8)\end{array}$ \\
\hline
\end{tabular}

TABLE 3. SUMMARY OF AEWM TESTING (FLANGE WELDS)

\begin{tabular}{|c|c|}
\hline Weld Length Monitored & 62.8 feet \\
\hline Total Number of Welds Monitored & 39 \\
\hline Average Weld Length Monitored & 19.3 inches \\
\hline Total Number of Weld Passes Monitored & 668 \\
\hline Total Length of Weld Passes Monitored & 1,074 feet \\
\hline Total Number of AEWM Indications & 72 \\
\hline $\begin{array}{l}\text { Total Number of Valid Indications } \\
\text { (Percent of Tota1) }\end{array}$ & $\begin{array}{l}10 \\
(13.9)\end{array}$ \\
\hline $\begin{array}{l}\text { Total Number of Center Hit Indications } \\
\text { (Percent of Total) }\end{array}$ & $\begin{array}{l}45 \\
(62.5)\end{array}$ \\
\hline $\begin{array}{l}\text { Total Number of Unconfirmed Indications } \\
\text { (Percent of Tota1) }\end{array}$ & $\begin{array}{l}17 \\
(23.6)\end{array}$ \\
\hline
\end{tabular}


(radiography). One of those was of defect severity according to the AWS code. It was a slag inclusion 3-inches long.

Further breakdowns of the AEWM classification of various indications are shown in Table 4 (webs) and Table 5 (flanges). Comparing "valid" AE activity of web welds in relation to "center hits" and "unconfirmed" AE activity, about 20 percent of the "valid" indications had lowmenergy (events with truncated averages of about 100 ringdown counts) corresponding to an almost equal 23 percent of the "unconfirmed" indications having similar low energies. Both of those are contrasted to "center hits," which produced approximately 38.8 percent of the indications at similar low RDC levels. "Valid" flange indications had about 28 percent of the indications with RDC leve1s greater than 500 counts compared to 17 percent for "unconfirmed" indications and only 8 percent for "center-hit" indications.

A similar correlation did not exist for flanges. "Valid" flange indications having low RDC levels comprised 30 percent of the total number detected ( 3 of 10) compared to 31 percent for "center hits" (14 of 45), and 41 percent for "unconfirmed" indications (7 of 17). "Valid" AE indications from flange welds did not produce any activity equal to or greater than 500 ringdown counts compared to 4 percent (2 of 45) for "center-hit" indications and 6 percent ( 1 of 17) for "unconfirmed" indications. It should be noted that flange $A E$ data are somewhat suspect due to the inability of the present AEWM to accurately locate weld flaws when used with transducer array spacings less than 20 inches.

The AEWM report forms were reviewed to determine the number of indications that occurred close to edges of plates that might have been caused by flaws in runoff tabs or weld start/stop areas. Previously, GARD had performed shop tests at Allied Steel Company in Chicago, Illinois and had determined that the only flaws detected were caused by runoff tabs. Web welds had 5 "unconfirmed" indications within 8 inches of a plate edge. Most web welds did not employ runoff tabs. Extra plate width was provided, which was subsequently trimmed from the final webs. That material included the weld start/stop areas. The flanges had 13 indications, all "unconfirmed," that were located within 4 inches of the plates edges. That is significant since only 17 "unconfirmed" flaws wexe detected for flanges. If most of those were caused by flaws in runoff tabs, they would not be detected in any subsequent inspections, possibly explaining a majority of the flange "unconfirmed" indications. Since a large number of weld passes were deposited in building 
TABLE 4. AEWM INDICATION SUMMARY (WEB WELDS)

A. BY INDICATION TYPE

\begin{tabular}{|c|c|c|c|c|c|c|}
\hline \multirow{2}{*}{$\begin{array}{l}\text { AVG RINGDOWN } \\
\text { COUNT } \times 100\end{array}$} & \multicolumn{2}{|l|}{ VALID } & \multicolumn{2}{|c|}{ CENTER HIT } & \multicolumn{2}{|c|}{ UNCONF IRMED } \\
\hline & UNCLASSIFIED & CRACK & UNCLASSIFIED & CRACK & UNCLASSIF IED & CRACK \\
\hline 1 & 3 & 2 & 18 & 17 & 8 & 10 \\
\hline 2 & 4 & 4 & 9 & 10 & 12 & 8 \\
\hline 3 & 0 & 3 & 8 & 8 & 6 & 9 \\
\hline 4 & 0 & 2 & 6 & 6 & 3 & 7 \\
\hline 5 & 0 & 2 & 1 & 3 & 4 & 2 \\
\hline 6 & 1 & 3 & 3 & 1 & 2 & 3 \\
\hline 7 & 1 & 0 & 0 & 0 & 1 & 1 \\
\hline TOTAL & 9 & 16 & 45 & 45 & 36 & 40 \\
\hline
\end{tabular}

B. BY LOCATION IN WELDS

\begin{tabular}{|c|c|c|c|c|c|c|}
\hline \multirow{2}{*}{$\begin{array}{l}\text { PASS } \\
\text { NUMBER }\end{array}$} & \multicolumn{2}{|c|}{ VALID } & \multicolumn{2}{|c|}{ CENTER HIT } & \multicolumn{2}{|c|}{ UNCONF IRMED } \\
\hline & A FACE & B FACE & A FACE & B FACE & A FACE & B FACE \\
\hline 1 & 6 & 1 & 13 & 10 & 21 & 7 \\
\hline 2 & 8 & 3 & 22 & 26 & 29 & 7 \\
\hline 3 & 5 & 0 & 10 & 2 & 8 & 1 \\
\hline 4 & 1 & 1 & 6 & 0 & 2 & 0 \\
\hline 5 & 0 & 0 & 1 & 0 & 0 & 0 \\
\hline OTHER & 0 & 0 & 0 & 0 & 1 & 0 \\
\hline TOTAL & 20 & 5 & 52 & 38 & 61 & 15 \\
\hline
\end{tabular}


TABLE 5. AEWM INDICATION SUMMARY (FLANGE WELDS)

A. BY INDICATION TYPE

\begin{tabular}{|c|c|c|c|c|c|c|}
\hline \multirow{2}{*}{$\begin{array}{l}\text { AVG RINGDOWN } \\
\text { COUNT } \times 100\end{array}$} & \multicolumn{2}{|l|}{ VALID } & \multicolumn{2}{|c|}{ CENTER HIT } & \multicolumn{2}{|c|}{ UNCONF IRMED } \\
\hline & UNCLASSIFIED & CRACK & UNCLASSIFIED & CRACK & UNCLASSIFIED & CRACK \\
\hline 1 & 2 & 1 & 7 & 7 & 1 & 6 \\
\hline 2 & 2 & 1 & 6 & 7 & 1 & 2 \\
\hline 3 & 1 & 1 & 3 & 3 & 3 & 1 \\
\hline 4 & 0 & 2 & 7 & 3 & 0 & 1 \\
\hline 5 & 0 & 0 & 1 & 0 & 0 & 1 \\
\hline 6 & 0 & 0 & 1 & 0 & 1 & 0 \\
\hline TOTAL & 5 & 5 & 25 & 20 & 6 & 11 \\
\hline
\end{tabular}

B. BY LOCATION IN WELDS

\begin{tabular}{|c|c|c|c|c|c|c|}
\hline \multirow{2}{*}{$\begin{array}{c}\text { PASS } \\
\text { NUMBER }\end{array}$} & \multicolumn{2}{|c|}{ VALID } & \multicolumn{2}{|c|}{ CENTER HIT } & \multicolumn{2}{|c|}{ UNCONFIRMED } \\
\hline & A FACE & B FACE & A FACE & $B$ FACE & A FACE & B FACE \\
\hline 1 & 7 & 1 & 5 & 1 & 3 & 1 \\
\hline 2 & 0 & 0 & 4 & 3 & 2 & 1 \\
\hline 3 & 1 & 0 & 7 & 5 & 2 & 0 \\
\hline 4 & 0 & 0 & 3 & 2 & 1 & 3 \\
\hline 5 & 0 & 0 & 0 & 3 & 2 & 0 \\
\hline OTHER & 0 & 1 & 11 & 1 & 2 & 0 \\
\hline TOTAL & 8 & 2 & 30 & 15 & 12 & 5 \\
\hline
\end{tabular}


up the thick flanges, it is likely that flaws could be created in the runoff tabs due to the formation of trapped slag, porosity, or other defects.

For webs, the AEWM frequency spectra analyses, which classified AE indications as either cracks or unclassified flaws, categorized 16 "valid" indications to be cracks and 9 as unclassified flaws. It should be noted that slag in trapped inclusions may fracture and cause AEWM crack indications. Forty-five of 90 "center-hit" indications were considered cracks by the AEWM compared to 45 that were unclassified. Forty "unconfirmed" indications were categorized as cracks by the AEWM compared to 36 that were categorized as unclassified. For flanges, five of the "valid" indications were categorized as cracks compared to five that were categorized as unclassified. Twenty of the "center hit" indications were categorized as cracks compared to 25 that were categorized as unclassified. Eleven of the "unconfirmed" indications were categorized as cracks compared to six that were categorized as unclassified.

The mean RDC value for "valid" indications in web welds was 267 counts for unclassified flaws and 344 counts for crack indications. For the "center-hit" data, unclassified flaws had a mean $\mathrm{RDC}$ value of 238 counts compared to a mean of 236 counts for crack indications. "Unconfirmed" indications had a mean RDC value of 281 counts for unclassified indications compared to 290 counts for the crack indications. "Valid" indications for flanges had a mean RDC value of 180 counts for unclassified indications compared to a mean of 280 counts for crack indications. That is less than the mean "center-hit" value, which was 268 counts for unclassified indications compared to 210 counts for crack indications. For "unconfirmed" indications, the mean unclassified value was 300 counts and the mean crack value was 200 counts.

Laboratory analyses of the "valid," "center-hit," and "unconfirmed" indications recorded on floppy disks was performed by obtaining printouts of preprocessed $\mathrm{AE}$ data from regions where $\mathrm{AEWM}$ indications were detected. That data was manually reviewed in search of any parametric variations that might differentiate those types of indications. However, review of the data did not provide any significant variations that could be used to program the AEWM to discriminate between the three types of indications. It is likely that the "center-hit" and "unconfirmed" indications can be eliminated by other means. 


\section{AEWM PERFORMANCE DURING SHOP TESTING}

The large number of AEWM overcalls suggests that the AEWM is inaccurate. However, the test results are more reflective of the inspection method chosen. The best method for detecting flaws would have been to stop each test when an AEWM indication was detected and section the weld to confirm the presence of a flaw. In a production shop that is not possible. Probably, the "center hits" would have been eliminated by use of guard transducers. However, that was not determined until late in the test program.

It is likely that some subsurface flaws were overlooked during visual inspection ("unconfirmed" indications) and subsequently neglected when detected by conventional NDT personnel as they were not of defect severity. That an AEWM indication was "unconfirmed" does not completely impact on its existence or flaw type (crack, porosity or flag inclusion).

Many "unconfirmed" AE indications probably were caused by small flaws. The submerged-arc welding process has a high degree of self-purging due to its high heat input and deep-penetrating weld. It is possible for a small slag inclusion to be created in one weld pass and then melted out and eliminated by a successive pass. It is likely that some "unconfirmed" indications were of that nature. Many "unconfirmed" AEWM indications probably were either too small to be detected or considered a defect by conventional NDT, were missed by visual inspection, or were eliminated during the course of subsequent welding operations or metal removal.

The AEWM frequency spectra analyses did not assist in eliminating the "center-hit" or "unconfirmed" indications. However, they did assist in determining if a "valid" indication was detected, especially if multiple flaw indications were acquired from one weld location. The presence of a crack classification combined with multiple indications from one location was a good indicator of slag inclusions. Classification of the exact flaw type was not provided by the AEWM, at least for flaws encountered in the shop tests. 


\section{CONCLUSTONS}

The AEWM detects flaws as we11, if not better, than other forms of nondestructive testing. That is borne out by the fact that there were no AEWM undercalls or missed flaws detected by conventional nondestructive testing. Several flaws detected by the AEWM also were confirmed by radiography, but only one of those was considered to be a defect. That indicates the AEWM has sufficient sensitivity to detect code-rejectable flaws (defects), which is a fundamental requirement for its future use.

Primary objectives of the long-term shop tests were 1) to establish a large test data base and 2) to prove that the AEWM was not subject to undercalls (missed indications) compared to conventional NDT methods.

During most of the test program, the "center-hit" problem was attributed to flux crushing and it was felt that guard transducers would not resolve that problem. When that theory was eventually discounted, testing was continued without guard transducers. That was done to prevent slow test set-ups (required to affix more transducers) that might reduce the number of welds tested or interfere with shop operations.

The desire to prevent undercalls resulted in use of a high test sensitivity due to the AEWM gain settings, which yielded a large number of "unconfirmed" indications. The AEWM was probably detecting small flaws that were not easily confirmed by other methods of inspection. Lower gain settings would have reduced the number of "unconfirmed" overcalls. But, at some point, the AEWM might have missed a flaw or defect detected by other means (which was not desired at this point in the AEWM test program).

The shop testing was successful. A large number of welds were monitored with no undercal1s. However, the cause of the overcalls needs to be determined and they must be eliminated in future tests. The AEWM has proven capable of detecting code-rejectable defects. Its ability to detect flaws is somewhat offset by a relative inability to classify flaws both in type and severity. Its most obvious application would be as a NDT scanning tool to locate areas on welds for follow-up inspection using conventional NDT methods.

As previously noted, the submerged-arc welding process may be a source of defects. Also, there is considerable variability in the production rate of different welders based, in part, on their ability to judge whether a weldment is sound as it is being fabricated. The most useful feature of the AEWM is its ability to detect flaws as they are created on a weld-pass basis. The 
AEWM may be easily adapted to aid welders in evaluating their work in-process. That would increase the production rate of many welders and may prove to be its best application from a cost-savings standpoint.

The AEWM may assist fabricators in several important areas: 1) improving repair decisions, 2) detecting flaws, 3) qualifying weld procedures or welders, 4) reducing material handling in a shop and welder downtime to conduct conventional NDT inspections, and 5) reducing or eliminating post-weld repairs.

The AEWM has exhibited the potential for cost savings and improvements in weld quality for steel highway bridges. Savings and benefits may not only be accrued by fabrication shops, but also, by highway agencies employing them.

If the following recommended steps are instituted, it is likely that a significant impact may be achieved on fabrication shop operations during the next several years. Those actions should result in considerable savings. The time and cost required to institute the AEWM would be minimal compared with efforts previously expended to adopt ultrasonic testing and radiography for inspection of bridge welds. 


\section{ELIMINATION OF AEWM FALSE INDICATIONS}

Several issues need to be addressed to reduce the number of AEWM overcalls. Continued work is warranted to eliminate those overcalls and improve the AEWM to provide a more useful and practical tool.

False AEWM indications could be dealt with in several ways. It is likely that "center hits" are caused by "out-of-array" AE sources. If guard transducers are placed on a weldment intervening between the $\mathrm{AE}$ noise sources and the active array, AE noise will not be processed by the AEWM. That would eliminate "center hits." The AEWM has the third analog channel dedicated to this task and contains internal software to support the use of guard transducers. It would be useful to take the unit back to a fabrication shop and monitor welding operations using guard transducers. If no "center-hit" activity is encountered, that would indicate the guard setup has rejected "out-of-array" AE noise sources. The AEWM has been employed successfully on in-service bridges using that feature.

The solution to "unconfirmed" overcalls is simply to reduce the system gain until only defects are detected. That may entail AEWM testing at gains as low as $40 \mathrm{~dB}$, compared to the 50-60 dB employed in the High Steel tests. To determine the minimum acceptable system gain, the AEWM should be tested on a series of welds while progressively lowering the system gain until flaws are not detected. Then, the gain may be gradually increased until no flaws are overlooked during a number of tests. The resulting system gain should then be applied in all relevant test situations. That work could be performed simultaneously with tests aimed at eliminating "center hits."

\section{AEWM RECONFIGURATION}

If the AEWM is to be a practical shop tool, it should be utilized by welders. It is intended for QC-level inspection and welders make most QC decisions in terms of determining whether a weld is satisfactory during fabrication. A welder is usually the sole judge of whether or not an inprocess repair is warranted. The AEWM should be reconfigured to serve him.

Incorporating nondestructive testing into shop welding operations may be considered unusual. Oftentimes, NDT and shop production personnel have assumed adversary roles. That relationship should be revised. The AEWM should 
be a welder's tool to assist him in quickly determining whether a weld is flaw free.

The KTRP technician had very little technical background and no previous welding or NDT experience prior to this study. He was successful in completing his duties and operating the equipment. That suggests a welder also could serve as a NDT technician. If a separate technician were required to operate the AEWM during welding, it probably would not be economically practical.

The present AEWM requires no more than about 10 minutes to set up and calibrate once the unit has been moved to a welding area. Disassembly requires about half that time. A more adaptable unit that was user friendly to a welder would further reduce the test preparation time.

The unit should be reconfigured. The revised AEWM would be made simpler to operate. A welder would attach pre-connected transducers to the weldment. Then, he would press several buttons to sequentially activate and calibrate the equipment. As welders are often engaged in repetitive work, it would be possible for shop QC personnel to preset transducer spacing and system gain settings in the unit. Thereafter, a welder would only need to initiate a test, stop it, and possibly enter appropriate identification numbers for the weld being monitored.

It would be feasible to provide automatic calibration and gain controls whereby the unit would automatically pulse each transducer separately, determine the calibration distance, and set the system gain to provide the proper test sensitivity. Start/stop controls could be incorporated into any welding machine that would automatically start the AEWM when a weld was being deposited and subsequently stop it when the weld was completed. The AEWM could be operated with timing devices to indicate the duration of each welding operation. Data for each weld pass would be recorded and subsequently stored in battery-backed RAM memory of the reconfigured AEWM. The battery-backed RAM memory would allow stored test data to be retained when the unit was unpowered.

The reconfigured unit could incorporate an alphabetic/numeric key pad that would allow the entry of weld identification numbers and other QC-related data that would help identify a weldment or provide other useful information. Also, the unit could be connected to a simple "go-no go" weld parameter 
monitor that would continuously check welding machine settings to verify that the welding process was being performed in a suitable manner.

Once the AEWM was calibrated, the welding operation would automatically start recording $A E$ signals and any other relevant in-process data that would be stored on the battery-backed RAM. After a test was completed, the stored data would either be output to a self-contained printer or a microcomputer.

A simplified lockout system has been proposed by KTRP that would require only one guard transducer to eliminate "out-of-array" noise. That proposed system should be investigated. If proven workable, it would be quicker and easier to apply than the current guard system.

The reconfigured unit also would be equipped with audio and visual alarms and indicating lights to provide operational information. Lights would indicate that both transducers had been successfully calibrated. The system also would have a real-time visual readout for locating a flaw in relation to one transducer and providing some degree of flaw characterization as to severity and type. Audio annunclators would be incorporated to indicate if a test was not progressing satisfactorily (if no $\mathrm{AE}$ events were being detected). Another audible alarm would alert the welder when a flaw has been detected.

Improvement is needed in the manual adjustment and visual indication of system gain. The present AEWM has three indicating lights for determining the amplification of $\mathrm{AE}$ activity. Those provide an inadequate determination of what is occurring during the welding process. When very high-level $\mathrm{AE}$ activity occurs, the indicating lights on the front panel do not provide warning that the system gain has been set too high and that the unit will not function. The manufacturer needs to provide gain/AE activity indication over a wider range.

The reconfigured AEWM would be simpler to operate than the present unit. It would also be smaller and lighter for better mobility. At this time, battery power is not considered necessary. The new AEWM would be sealed totally and dustproof. Also, it would be shock resistant since it occasionally may be subjected to rough handling.

The unit also would be reasonably low in cost. The new AEWM would not be more than three to four times the cost of an analog ultrasonic testing device. Currently, a major $\mathrm{AE}$ monitoring problem area is in the sensing of $\mathrm{AE}$ activity. The main problem concerns coupling of transducers to steel plates. Improper coupling is usually due to flux that gets between the transducer and the plate surface weakening sound transmission (Figure 22). Also, extremely 


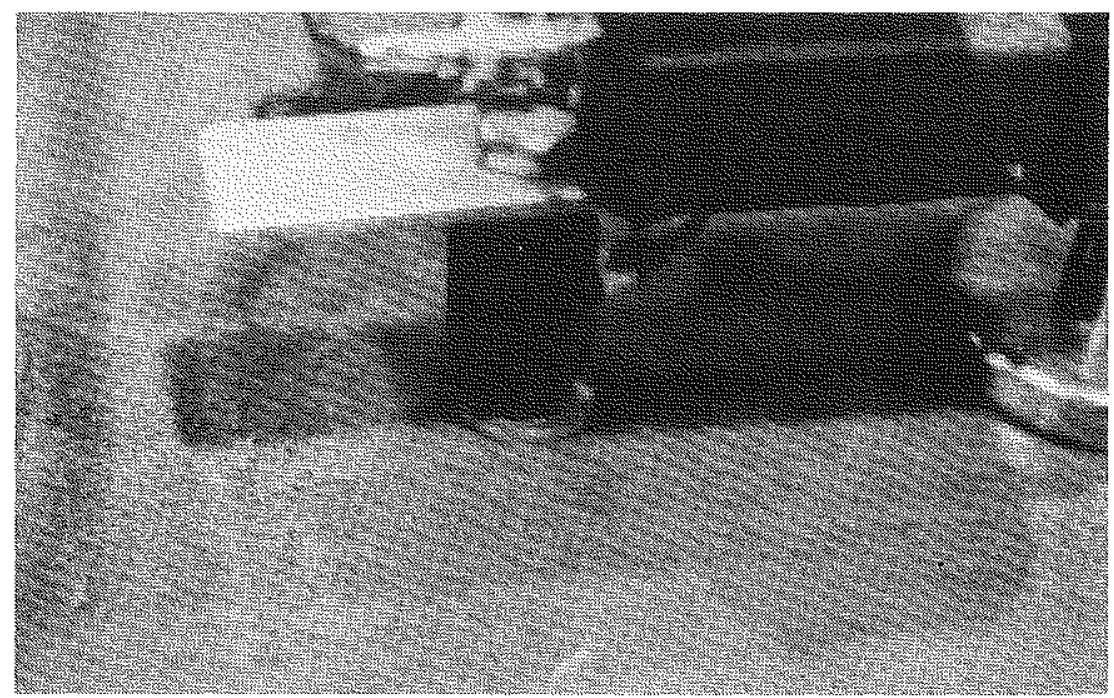

Figure 22. Transducer Assemb1y Coupled to Weldment (Note the flux near point of attachrent and extruded clear couplant around the base of the transducer). 
high temperatures may affect the viscosity of a couplant, changing the transmission quality of $\mathrm{AE}$ signals across the transducer/plate interface during a test (especially when monitoring flange welds). Another potential problem occurs when a transducer is bumped or a transducer lead wire is moved, causing the transducer to slide along a plate. This occurs even when using heavy magnetic-based hold-down units that attach the transducer to the steel with high force. That is one reason to have an audible confirmation during the test to indicate to a welder the unit is detecting $\mathrm{AE}$ activity.

Development of mechanically coupled transducers is recommended to eliminate the coupling problems encountered with the conventional transducers. That type of transducer has a conical metal wave guide tapered to a fine point that is glued to the face of a conventional low-temperature transducer. The wave guide/transducer assembly is attached to a spring-mounted fixture that forces the tip of the wave guide into the surface of the steel plate. Since the point of contact is small, a high coupling pressure is achieved providing sound transmission between the plate and transducer.

Mechanically coupled transducers would eliminate the need for siliconetype couplants, which have proved troublesome. Several attendant benefits would be gained. The new transducers would provide more consistent coupling to weldments. That would allow more confidence in the preselection of gain settings for particular weldments. Mechanically coupled transducers would be easier and quicker to attach to welds. If a tranducer were disturbed, it could be designed to slide and yet recouple quickly without significant loss in coupling efficlency. Those tranducers could be used on both webs and flanges (that are subject to high preheating temperatures).

\section{FUTURE AEWM TESTING}

Prior to AEWM reconfiguration and field testing using welders as AEWM operators, several preliminary tests should be performed. An initial test should be conducted to prove that "center hits" can be eliminated by guard transducers. If "center hits" are eliminated, that would fix the source of the $\mathrm{AE}$ activity as "out-of-array" indications probably caused by arcing or some related phenomena. During those tests, reduced system sensitivity would be employed by monitoring at lower gain settings ( 40 to $45 \mathrm{~dB}$ ) to eliminate many "unconfirmed" overcalls.

GARD is presently developing the Acoustic Enission Bridge Monitor (AEBM) for the FHWA. That unit should be completed and field-tested on bridges by 
the time this study is completed. That unit employs advanced computer technology and has many of the features recommended for a reconfigured AEWM. The new AEBM should be modified to contain software that allows the simplified lockout of "out-of-array" AE activity. Also, better detection and flaw characterization capability may be provided by the new unit, which has higher resolution for flaw location.

Laboratory tests should be performed using the AEBM to develop mechanically coupled transducers and the simplified guard system. It should be noted that those new features also would be beneficial in field monitoring of bridges. Then, laboratory testing would be performed to determine methodology for making repair and weld conditioning decisions based solely on AEBM results. That would be accomplished by inducing weld conditions that might produce flaws. A weld would be deposited and the AEWM would predict whether a repair should be made. Thereafter, the weld would be sectioned and the correctness of the AEBM evaluation would be determined.

Upon completion of the laboratory tests, the AEBM should be taken to a fabrication shop and tested for a 30-day period. After that test, a specification should be prepared for the reconfigured AEWM. Once that unit was completed, it would be taken to a fabrication shop, and shop tested for 3 to 6 months. At the fabrication shop, welders would be trained to use the AEWM and would incorporate it into their welding operations. They would be requested to increase their reliance on repair decisions based upon AEWM test results. At the same time, $Q C$ personnel would be furnished with hard-copy test results and would be requested to correlate those results with the final shop QA testing and any shop QC nondestructive testing. The progress of welders in adapting to the equipment would be monitored. Welders would be solicited for suggestions on use of or modifications to the new AEWM.

By the end of the shop tests, a significant quantity of data would be compiled relative to operation of the reconfigured AEWM. That data would serve as a basis for convincing state agencies, regulatory groups, and societies that the reconfigured AEWM should be incorporated in their codes, regulations, and specifications. At the same time, the reconfigured AEWM would be turned over to the same fabrication shop and used unassisted for a period of 6 months. Their work would be documented providing a basis for further implementation of the AEWM. 


\section{FUTURE APPLICATION OF THE AEWM}

The greatest benefit of the AEWM will be realized only when its full utilization is permitted by state and national codes, regulations, and specifications. AEWM test results should be permitted to replace in-house QC nondestructive testing norma1ly conducted randomly on a percentage of the welds applied. It should be emphasized that this is only for QC testing and not for $Q A$ testing. The purpose of $Q C$ nondestructive testing is to reduce the number of defects encountered by QA testing and to maintain the quality of routine welding operations at an acceptable leve1. The AEWM is well suited for that task. After a significant amount of shop experience has been gained with the unit, it may be possible to limit conventional QA nondestructive inspections to locations where the AEWM encountered flaw indications. Those inspections might supplant the random or 100 percent nondestructive testing that states currently require on some bridge weldments.

The AEWM could be used in lieu of prequalification tests for welders and weld procedures. Oftentimes, fabricators are confident that their personnel and weld methods are satisfactory. However, highway agencies require "goodfaith" pretests to assure that the shop produces quality weldments. If a shop were willing to submit to the continuous inspection provided by the AEWM, that should be sufficient to prove a fabricator's personnel and weld procedures were satisfactory. The elimination of prequalification tests would result in considerable savings by both fabricators and highway agencies. 

APPENDIX

AEWM REPORT FORM 
Sheet No

Weldment No

Date

Shift No
KTRP NDI

High Steel NDI

Weldment Length in

Total Weld Length Monitored in

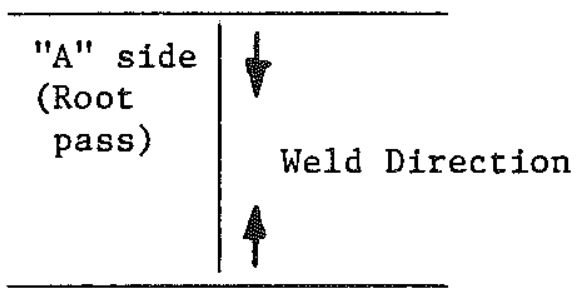

Plate Stee1 ASTM

Plate Thickness

Weld Preparation

Plate Width

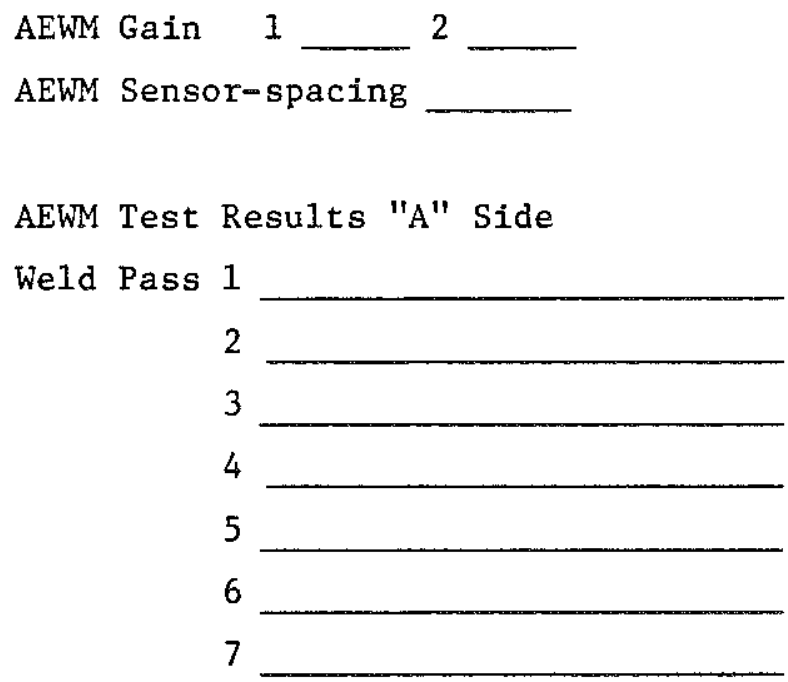
in

in

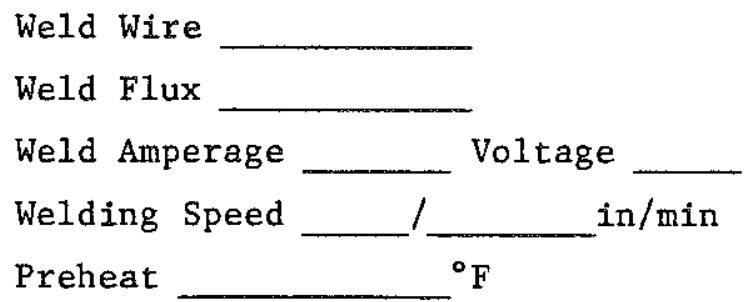

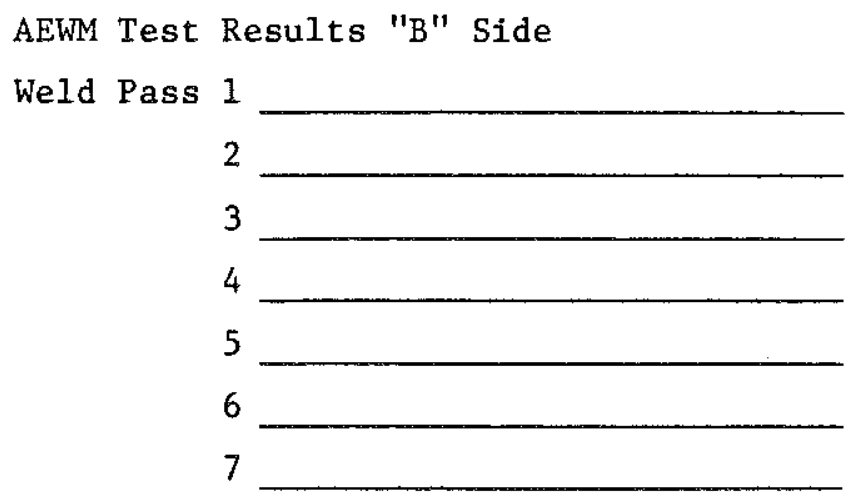

Comments:

High Steel Test Results: 


\section{REFERENCES}

1. Prine, D. W., "Improved Fabrication and Inspection of Welded Connections in Bridge Structures," GARD Inc,, Niles, Illinois, FHWA Report No. FHWA/RD-83/006, October 1984.

2. Hopwood, T. and Deen, R. C., "Demonstration and Preliminary Evaluation of the Acoustic Emission We1d Monitor," University of Kentucky Transportation Research Program, Lexington, Kentucky, Report No. UKTRP-85-23, June 1985. 


